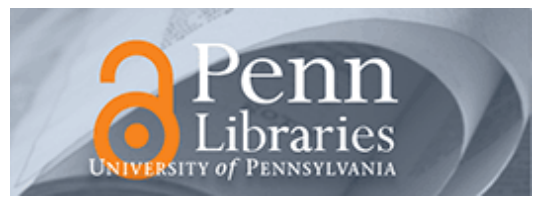

University of Pennsylvania

ScholarlyCommons

Accounting Papers

Wharton Faculty Research

4-2015

\title{
Strategic Silence, Insider Selling and Litigation Risk
}

Mary Brooke Billings

Matthew C. Cedergren

University of Pennsylvania

Follow this and additional works at: https://repository.upenn.edu/accounting_papers

Part of the Accounting Commons, and the Economics Commons

\section{Recommended Citation}

Billings, M., \& Cedergren, M. C. (2015). Strategic Silence, Insider Selling and Litigation Risk. Journal of Accounting and Economics, 59 (2-3), 119-142. http://dx.doi.org/10.1016/j.jacceco.2014.12.001

At the time of publication, author Matthew C. Cedergren was affiliated with New York University. Currently (October, 2014), he is a faculty member at the Accounting Department at the University of Pennsylvania.

This paper is posted at ScholarlyCommons. https://repository.upenn.edu/accounting_papers/16

For more information, please contact repository@pobox.upenn.edu. 


\title{
Strategic Silence, Insider Selling and Litigation Risk
}

\begin{abstract}
Prior work finds that managers beneficially time their purchases, but not sales, prior to forecasts. Focusing on if (as opposed to when) a forecast is given, we link insider selling to silence in advance of earnings disappointments. This raises the question of whether the absence of incriminating trading drives reductions in litigation risk potentially attributed to warnings. We find that the absence of a warning combined with the presence of selling exacerbates the consequences associated with the individual behaviors. Yet, selling prior to a warning typically does not offset all of the warning's benefit. In so doing, we supply the first robust evidence of a litigation benefit associated with warning.

\section{Keywords}

disclosure, earnings guidance, insider trading, litigation risk, earnings disappointment, negative earnings news

Disciplines

Accounting | Economics

\section{Comments}

At the time of publication, author Matthew $\mathrm{C}$. Cedergren was affiliated with New York University. Currently (October, 2014), he is a faculty member at the Accounting Department at the University of Pennsylvania.
\end{abstract}




\title{
Strategic silence, insider selling and litigation risk
}

\author{
Mary Brooke Billings* \\ New York University \\ mbilling@stern.nyu.edu \\ Matthew C. Cedergren \\ New York University \\ mcedergr@stern.nyu.edu
}

December 2014

Journal of Accounting and Economics, forthcoming

\begin{abstract}
Prior work finds that managers beneficially time their purchases, but not their sales, prior to their forecasts. Shifting attention from when forecasts are given to if a forecast is given, we link insider selling to silence in advance of an earnings disappointment. In particular, our evidence indicates that managers who deliver disappointing news next quarter are less likely to bundle a warning with the current quarter's earnings announcement as the amount of shares they sell in the two-week trading window immediately following the current quarter's earnings announcement increases. These findings suggest that managers rely on a subtle form of opportunism-simply remaining quiet, selling shares in this quarter's heavily trafficked, typically open trading window, and then waiting for the earnings disappointment to reveal itself next quarter-as opposed to engaging in the overtly opportunistic approach of selling shares just prior to supplying a warning about next quarter along with this quarter's earnings. This raises the question of whether the absence of incriminating trading, as opposed to the presence of a cautionary warning, drives reductions in litigation risk potentially attributed to warnings. Analyzing earnings-disclosurerelated lawsuits, we find that the absence of a warning combined with the presence of selling exacerbates the consequences associated with the individual behaviors. Yet, selling prior to a warning typically does not offset all of the warning's benefit. In so doing, we supply the first robust evidence of a litigation benefit associated with warning - even after considering the role that managers' trading behavior plays in shaping their disclosure decisions and influencing the firms' litigation consequences.
\end{abstract}

Keywords: disclosure; earnings guidance; insider trading; litigation risk; earnings disappointment; negative earnings news

\section{JEL Classifications: M41; K22; G14}

This paper benefited from the insightful comments of Bob Holthausen, Bob Jennings, April Klein, Alastair Lawrence (our AAA discussant), Baruch Lev, Stephen Ryan, Bixia Xu (our CAAA discussant), Jim Wahlen, an anonymous referee and participants at the 2014 American Accounting Association Annual Meeting and the 2014 Canadian Academic Accounting Association Annual Conference.

- Corresponding author: Mary Billings, New York University, Stern School of Business, Suit 10-94, 44 West Fourth Street, New York, NY 10012. Telephone: 212-998-0097. Fax: 212-995-4004. E-mail: mbilling@stern.nyu.edu. 


\section{Introduction}

Skinner (1994) finds that 25\% of firms facing large, negative earnings news voluntarily warn of the bad news, compared to $6 \%$ of the firms facing large, positive news. ${ }^{1}$ He argues that these findings result from managers' fear of legal liability. Empirical evidence in support of this theory is mixed (Healy and Palepu 2001), with some recent work finding that bad news warnings do not trigger litigation and may potentially deter certain types of litigation (Field et al. 2005) but still other work arguing that warnings prompt lawsuit filings (Johnson et al. 2007). In the event of a lawsuit, warnings do appear to play a role in lowering settlement costs (Skinner 1997). If managers can indeed lower litigation costs by warning, why do most managers remain silent when facing earnings disappointment? In Skinner (1994)'s sample of firms facing large, negative news, $75 \%$ of managers elected not to warn. Studying a more recent time frame, we find remarkably similar rates of silence: our evidence indicates that $74 \%$ of firms facing impending negative news fail to warn. Further, when we narrow our focus to firms with a recent history of supplying guidance, the rate of silence only falls to $52 \%$. In this paper, we investigate whether managers who remain silent in the face of earnings disappointment engage in insider selling to exploit knowledge of the impending shortfall and, if so, how this opportunism affects firms' litigation risk.

Prior research connects insider trading with opportunistic disclosure behavior. In early work, Penman (1982) provides evidence that managers benefit from timing their trades around their forecasts of annual earnings. Noe (1999) builds on this finding to show that managers' opportunistic trading occurs after, but not before, they deliver a forecast. In more recent work, Cheng and Lo (2006) provide evidence that managers opportunistically adjust their forecasting activity when they purchase shares. Yet, they find no evidence to suggest that managers

\footnotetext{
${ }^{1}$ Managers voluntarily warn of negative news via their earnings guidance (as captured in either an earnings forecast or an earnings preannouncement). In this paper, we use the terms "disclosure" and "guidance" interchangeably.
} 
strategically adjust either the frequency or the timing of their earnings guidance when they sell shares, conjecturing that litigation concerns likely cause managers to avoid selling shares prior to issuing bad news forecasts. Also consistent with a reluctance to engage in blatant opportunism, Huddart et al. (2007) find that insiders abstain from profitable trade immediately prior to earnings announcements and, instead, trade heavily after earnings announcements (but prior to the filing of the formal report) during a time when the legal risks associated with insider trading are lower. Thus, evidence indicates that managers time both their trades and forecasts to exploit information asymmetries, but that legal fears constrain overt opportunism associated with insider selling immediately prior to the delivery of negative earnings news.

Building upon these findings, we investigate the link between insider selling and the decision to warn in the face of impending negative earnings news. In contrast to prior work that links the timing of a forecast to insider purchasing, we connect strategic silence (i.e., the absence of a warning) to insider selling. In so doing, we shift attention from when forecasts are given to if a forecast is given when there is increased incentive to do so. Focusing on the quarterly decision to supply earnings guidance, we document a link between the failure to warn of impending earnings disappointment and insider selling. Consequently, we supply evidence that speaks to the question of why managers may fail to warn even if it is in the firm's best interest for them to do so.

As mentioned, prior work typically examines trading behavior conditional upon the presence of a forecast-i.e., prior work begins with a sample of forecasts and examines the timing of a trade in relation to the timing of a forecast. Our research design, however, acknowledges the evolving disclosure and trading environment that managers now confront. In particular, we conduct our analysis at the firm-quarter level and focus on whether a forecast is given (as opposed to the timing/frequency of forecasts) for two main reasons. First, the overwhelming majority of guidance now arrives bundled with a quarterly earnings release. Over 
our sample period, approximately $80 \%$ of all forecasts are bundled and, in later years, the proportion climbs above $90 \%$. Accordingly, the decision to guide increasingly appears to be made on a quarterly (as opposed to a day-to-day) basis. Second, company-level regulation of insider trading generally precludes trading prior to earnings announcements and typically encourages insiders to concentrate their trade in the days shortly after earnings announcements. ${ }^{2}$ As a result, managers increasingly make disclosure and trading decisions on a quarterly basis and in temporal proximity. These trends reduce managers' control over the timing of both forecasts and trades. Yet, managers can and do control whether or not they issue a forecast. Thus, because we expect that managers now have less power to time their trades or their forecasts, we turn our attention to the question of whether trading incentives help to explain whether managers choose to warn or to remain silent in the face of impending bad news.

We examine an initial sample of 107,307 quarterly earnings announcements made during the decade since Regulation Fair Disclosure ("Reg FD") took effect in October 2000. We focus on the firm-quarter observations in which managers face impending negative news, as measured by the delivery of disappointing earnings news in the next quarter. Because it is not possible to cleanly identify the point at which managers learn of negative earnings news, this approach to measuring impending negative earnings news categorizes all managers of firms that report negative earnings news next quarter as possessing this knowledge on or before the earnings announcement associated with the current quarter. The measurement error associated with this approach likely reduces our ability to detect significant relations in the data: if managers do not possess the negative news yet, then they do not have an incentive to sell and, thus, their selling

\footnotetext{
${ }^{2}$ Bettis, Coles and Lemmon (2000) document that over $92 \%$ of their sample firms have a policy in place to regulate insider trading, with $78 \%$ of firms having explicit blackout periods in place to preclude insider trades. Examining the specifics of the policies, they note that " $[\mathrm{t}] \mathrm{h}$ e single most common policy disallows trading by insiders at all times except during a trading window that is open during the period 3 through 12 trading days after the quarterly earnings announcement." (Page 192) Consistent with the notion that increased jeopardy accompanies trades that occur during blackout periods, Huddart, Ke and Shi (2007) find that insiders disproportionately concentrate their trade in the days immediately following quarterly earnings releases.
} 
behavior should not correlate with their decision to warn of this yet-to-be-learned news. ${ }^{3}$

Consequently, our empirical tests investigate whether trading considerations appear to factor into the decision to "bundle" a bad news warning with the current quarter's earnings announcement (or, alternatively, the decision to remain silent) for managers who face impending earnings disappointment next quarter.

We find that managers who disappoint investors with negative earnings news next quarter are less likely to bundle negative earnings guidance with the current quarter's earnings news when they sell more shares in the two-week trading window following the current quarter's earnings announcement. That is, the likelihood of warning decreases with insider selling. The observed relation between silence and selling strengthens when we focus exclusively on the firm-quarters when the decision to warn versus trade is most relevant. Specifically, the observed relation strengthens when we limit attention to recent and frequent guiders, when we further narrow our focus to cases where managers deliver positive current-quarter earnings news followed by negative earnings news next quarter, when we focus exclusively on trades of the CEO and CFO, and when we use the classification scheme of Cohen et al. (2012) to identify opportunistic sales. ${ }^{4}$ Thus, our evidence suggests that trading incentives help to explain why managers, particularly those committed to the practice of supplying guidance, remain silent even when prior evidence suggests that legal liability might provide incentives for them to bundle a warning with the current quarter's earnings news.

Further analysis provides additional evidence that the silence we observe is strategically motivated. In addition to evidence linking the failure to warn with increased selling, we find that

\footnotetext{
${ }^{3}$ A wealth of prior literature provides evidence that managers trade in the quarters leading up to important information releases, including dividend announcements (John and Lang 1991), repurchases of stock (Lee et al. 1992), equity offerings (Karpoff and Lee 1991), bankruptcy filings (Seyhun and Bradley 1997), and 10-Q/10-K filings (Huddart et al. 2007). Further, focusing specifically on trading in advance of earnings disappointment, Ke et al. (2003) find insider selling increases up to nine quarters prior to a break in a string of consecutive increases in quarterly earnings, while Hugon and Lee (2014) find that insiders' 10b5-1 sales predict weakening earnings performance many quarters in advance, which is consistent with earlier evidence in Jagolinzer (2009).

${ }^{4}$ As discussed in Section 5, narrowing our focus even further to "committed" guiders mitigates concern that unobserved firm characteristics explain the inability/failure to warn, as these firms routinely provide guidance.
} 
managers are more likely to bundle positive earnings guidance with the current quarter's earnings news as the amount of shares they sell in the post-disclosure trading window increases, even when facing impending negative news. Hence, insider selling is not associated with a general unwillingness to use guidance to communicate with investors (i.e., managers who trade are not always more likely to stay silent). Rather, the desire to sell shares at artificial prices appears to influence managers' selective/tactical silence.

Consistent with legal fears constraining opportunism, we find that managers are more likely to warn of negative news (and are also more likely to abstain from delivering a positive or confirming forecast) as ex ante litigation risk increases. That is, managers of firms that face increased risk of litigation are less likely to engage in strategic silence and, instead, are more likely to warn of the impending negative news. Hence, the incentive to warn trumps the incentive to exploit information asymmetries for some (but not all) managers-particularly those whose firms have higher ex ante litigation risk.

Further, among managers who do engage in strategic silence, we find that the decision to remain silent links to insider selling that concentrates in the two-week, typically open trading window following the current quarter's earnings release. This suggests that strategically silent managers avoid the increased personal legal jeopardy associated with selling shares immediately prior to a negative news revelation. Instead, they execute their sales in a manner that both distances their sales from the market's eventual receipt of the negative earnings and allows them to potentially explain away their sales as taking place within the confines of the firms' insider trading regulations and, as such, part of their routine trading patterns. This covert approach to opportunism - simply remaining quiet, selling shares in this quarter's open trading window, and then waiting for the earnings disappointment to reveal itself next quarter-contrasts with the more risky approach of selling shares just prior to the market's receipt of negative earnings news. 
The evidence discussed above indicates that the managers who are "good" disclosers (i.e., likely to warn) are more likely to be "well-behaved" traders (i.e., less likely to sell opportunistically). This raises the question of whether the absence of incriminating trading behavior, as opposed to the presence of a cautionary warning, drives reductions in litigation risk potentially attributed to disclosure. Consequently, we next turn our attention to a sample of firms that experience earnings-related lawsuit filings in order to examine whether the failure to warn, opportunistic insider sales, and/or the interaction of these two behaviors prior to the market's receipt of negative earnings news link to increased litigation risk for the firm. Examining the trading and disclosure behavior of these lawsuit firms (along with a group of propensity-matched control firms that do not experience such lawsuits), we find strong evidence that silence and selling each independently increase litigation risk. In addition, our evidence indicates that the interaction of silence and selling incrementally raises litigation risk. That is, the absence of a warning combined with the presence of insider selling exacerbates the consequences associated with the individual behaviors. The evidence also suggests that selling prior to a warning offsets some, but not all, of the warning's benefit for virtually our entire litigation sample. Thus, a warning still provides some protection against litigation, even if accompanied by selling.

Collectively, our findings suggest that trading incentives influence managers' guidance decisions and, in turn, trading and guidance jointly influence litigation risk. These findings highlight the tension between manager-level trading incentives and firm-level disclosure incentives: strategic silence interacts with opportunistic selling by managers to increase the litigation consequences borne by the firm. As mentioned, prior literature aiming to link opportunistic trade to opportunistic disclosure finds that managers beneficially time their purchases, but not their sales, prior to the delivery of a forecast (Cheng and Lo 2006). In this paper, we link beneficial insider selling to strategic silence (i.e., the forgone opportunity to 
supply a cautionary forecast) in advance of negative earnings news. That is, we provide evidence that trading incentives play a role in not just the timing but also the existence of a forecast. Consequently, in contrast to prior work's efforts to document overtly opportunistic selling immediately prior to the delivery of a bad news forecast, we document a more subtle form of opportunism - insider selling immediately following the forgone opportunity to warn of next quarter's earnings shortfall.

In addition to contributing to the literature examining the extent to which insiders exploit information asymmetries, this paper's findings have important implications for the vast literature that studies the factors that influence managers' disclosure incentives. Absent direct examination of trading-based hypotheses, studies often exclude trading considerations when modeling managers' guidance decisions (Rogers and Van Buskirk 2013). Yet, our paper documents a significant correlation between trading and the decision to guide. As such, our findings underscore the importance of considering the interplay between managers' disclosure and trading behavior when studying the costs and benefits associated with disclosure.

Finally, a long-standing and important question in the disclosure literature focuses on whether cautionary warnings of impending bad news deter or trigger litigation. Early evidence suggests that voluntary disclosure does not prevent litigation (Skinner 1997) and, in fact, may even prompt it (Francis et al. 1994). Some recent work, however, indicates that warnings do not trigger litigation and, instead, potentially deter certain types of litigation (Field, Lowry, and Shu 2005), though the evidence on deterrence is weak. Yet, other recent work continues to suggest that warnings elicit lawsuit filings (Johnson, Nelson and Pritchard 2007). In this study, we combine insights from Field et al. (2005) and Johnson, Nelson and Pritchard (2007) to provide the first robust evidence of a litigation benefit associated with disclosure - even after considering the role that managers' trading behavior plays in shaping their disclosure decisions and influencing the firms' litigation consequences. 
The remainder of this paper progresses as follows. Section 2 provides background and discusses the related literature, while Section 3 develops the hypotheses. Section 4 describes the sample selection criteria and data collection procedures, while Section 5 presents the empirical analysis of the link between silence and insider selling in the face of impending bad news. Section 6 presents the litigation risk analysis. Section 7 concludes the study.

\section{Background on the interplay of disclosure, insider trading and litigation risk}

A typical class action shareholder lawsuit brought under Rule 10b-5 of the Securities Exchange Act of 1934 alleges that managers of the company made false or misleading statements and/or failed to disclose material adverse information in a timely manner to the market, resulting in a period of time when the firm's stock price was artificially inflated. The class of investors (known as the "plaintiff class") who purchased the company's stock during this time (known as the "class period") claims damages that result from managers' inadequate disclosure. The revelation of negative news as manifested by a considerable drop in the firm's stock price often triggers the filing of a shareholder lawsuit. Plaintiffs' attorneys can and do use managers' trading behavior during the class period as evidence of delayed disclosure and intent of wrongdoing (i.e., scienter) when filing the lawsuit and negotiating the settlement (Sale 2002, Johnson et al. 2007).

Although nearly all shareholder lawsuits brought under Rule 10b-5 settle before trial, settlements often result in sizeable costs to the firm and/or the firm's insurance provider. Despite the passage of the Private Securities Litigation Reform Act ("PSLRA") in December of 1995, which was intended to protect publicly traded firms from abuse of class action securities litigation, both the number of lawsuits filed and the average settlement amounts surged in the late 
1990s and early 2000s, and have generally remained at those levels since then. ${ }^{5}$ Shareholder lawsuits under Rule 10b-5 and their associated resolution costs form the basis of the preemption hypothesis introduced by Skinner (1994).

Skinner (1994) suggests that aversion to legal liability causes managers to voluntarily warn of negative news. In particular, Skinner (1994) hypothesizes that U.S. securities laws provide incentives for managers to disclose negative news voluntarily. Because announcements of large, negative earnings surprises increase the likelihood of potentially costly 10b-5 lawsuits, he argues that managers benefit from warnings because such preemptive disclosures both reduce the plaintiffs' ability to claim that managers failed to release material information promptly and limit the size of the plaintiff class by reducing the period of nondisclosure. As such, Skinner suggests that the costs of failing to disclose bad news exceed the costs of failing to disclose good news. In fact, legal liability provides disincentive to disclose good news, as managers may be held accountable for ex post optimistic good news forecasts.

Early work provides mixed evidence to support the premise that voluntary disclosure reduces litigation consequences (Healy and Palepu 2001). Examining a litigation sample of 45 observations covering 1988 to 1992, Francis et al. (1994) find that managers' warnings prompted 28 of the lawsuits, which suggests that warnings do not always deter, and in certain cases may even trigger, lawsuit filings. ${ }^{6}$ Arguing that the control sample of similarly "vulnerable" firms used by Francis et al. (1994) differs from the lawsuit sample in, among other respects, size and the extent to which the market expected the adverse news, Skinner (1997) re-examines the relation between disclosure and litigation. Unlike Francis et al. (1994), Skinner (1997) uses the litigation firms as their own controls by comparing the firms' disclosure behavior during quarters

\footnotetext{
${ }^{5}$ See http://blogs.law.harvard.edu/corpgov/2013/08/04/2013-mid-year-securities-litigation-update/ or http://securities.stanford.edu/clearinghouse research/2013 YIR/Cornerstone-Research-Securities-Class-Action-Filings-2013MYA.pdf for details.

${ }^{6}$ Francis et al. (1994) select a control sample of "at risk" firms that experienced earnings declines that were, on average, 50 percent more than the average declines reported by the sample of firms in the same industries that were subject to litigation. They find that 46 of 53 of these control firms similarly vulnerable to litigation did not warn of the impending negative news.
} 
when they faced litigation to their disclosure behavior during quarters when they did not face litigation. Like Francis et al. (1994), however, Skinner (1997) finds evidence that early disclosure does not prevent litigation, as disclosure during lawsuit quarters is more timely than disclosure during non-lawsuit quarters.

Studies focusing on the relation between disclosure and the incidence of litigation must consider that disclosure behavior and the probability of litigation are endogenous to the severity of the news, making it difficult to disentangle the effect of disclosure on the probability of litigation. Using a simultaneous equations methodology, Field et al. (2005) find evidence that is inconsistent with the notion that warnings trigger litigation and, instead, provide weak evidence that early disclosure deters certain types of litigation. ${ }^{7}$ As such, in contrast to prior work, Field et al. (2005) supply some evidence to suggest that managers' disclosure decisions may lower firms' litigation risk.

Although the literature examining the link between litigation and disclosure typically excludes trading considerations from their analyses, a study by Johnson et al. (2007) is the exception. Using a research design that does not account for the endogeneity concerns highlighted by Field et al. but that does consider the link between trading and litigation, Johnson et al. (2007) find that litigation likelihood increases with both the presence of abnormal trading and earnings warnings. Thus, absent efforts to tackle endogeneity or to consider the interplay between disclosure and trading, this work offers no support for a deterrence effect to warnings and, instead, suggests that disclosure and trading both prompt lawsuit filings.

In summary, recent evidence indicates that disclosure may reduce firms' litigation risk, as well as their lawsuit settlement amounts. Yet, none of this research considers whether trading incentives influence the likelihood that a manager supplies a negative news warning or whether

\footnotetext{
${ }^{7}$ In particular, Field et al. (2005) do not detect a significant coefficient on their warn instrument in their main analysis (see their Table 4), but do detect significance at the $5 \%$ level for a one-tailed test when they remove lawsuits that were dismissed from the sample (see their Table 5).
} 
the combination of silence and selling influences firms' litigation risk. Do trading incentives help explain why some managers forego the potential benefits associated with preemptive warnings? And, if the silent managers also trade opportunistically in the face of impending earnings disappointment, this raises the question of whether the presence of incriminating selling behavior, as opposed to the absence of a preemptive warning, drives the increased litigation risk potentially attributed to non-disclosure in the Field et al. study.

\section{Hypotheses}

Managers face both disclosure and trading decisions when they learn of impending negative news. Although securities laws provide penalties for failing to disclose material news in a timely manner, trading opportunities might cause some managers to stay quiet. If managers trade prior to disclosing the negative news, litigation consequences associated with delayed disclosure may increase, as shareholders' attorneys can and do use trading behavior as evidence of managers' disclosure delays (Sale 2002; Johnson et al. 2007). Because the strength of the plaintiffs' case largely depends on the assertion that managers knowingly withheld adverse information, managers may improve the plaintiffs' bargaining position by trading prior to the market's receipt of the negative news. Yet, some managers might remain quiet (i.e., fail to supply a cautionary forecast) in order to sell shares at inflated prices because the firm (and its directors' and officers' liability insurance carrier) may suffer most of the consequences. Although prior research documents increased turnover among managers following both lawsuit filings and earnings restatements (Niehaus and Roth 1999, Desai et al. 2006), managers' trading behavior does not appear to increase turnover rates within lawsuit firms. ${ }^{8}$

\footnotetext{
${ }^{8}$ Because the firing of top executives could strengthen the bargaining position of plaintiffs during settlement negotiations (as it may offer support for claims of a manager's wrongdoing), firms may be less likely to replace CEOs immediately following the filing of a shareholder lawsuit. Consistent with this notion, Billings (2008) finds no evidence to suggest that trading behavior
} 
Nonetheless, as mentioned earlier, prior evidence suggests that managers are reticent to engage in overtly opportunistic selling prior to negative news warnings. These findings do, however, suggest that managers formulate their trading decisions in concert with their disclosure decisions. Thus, while managers who choose to warn are reticent to sell shares immediately prior to a warning, managers may be willing to engage in a subtler form of opportunism: managers may remain silent in the face of impending negative news in order to dispose of shares in the open trading window immediately following the current quarter's earnings announcement.

Among the managers who do remain silent, we expect the presence of firm-level insider trading restrictions to influence when they choose to exploit knowledge of the impending bad news. In particular, as depicted in Figure 1, we expect that the decision to remain silent will link to insider selling that is concentrated in the low-jeopardy, typically open trading window (i.e., "green sales" trading window) following the announcement of the current quarter's earnings, consistent with Bettis et al. (2000) and Huddart et al. (2007). ${ }^{9}$ This allows them to execute their trades in a manner that both distances their sales from the market's eventual receipt of the negative earnings and also allows them to potentially explain away their sales as taking place within the confines of the firms' insider trading regulations and, as such, part of their routine trading patterns.

At the same time, we do not expect to observe a link between the decision to warn and insider selling that is concentrated in the high-jeopardy, typically closed trading windows (i.e., the "lag red sales" and "lag yellow sales" trading windows) leading up to the announcement of the current quarter's earnings. In other words, we predict the presence of covert opportunism-

helps to explain turnover among managers of firms that faced earnings-disclosure-related (as opposed to fraud-based) shareholder litigation. Further, examining SEC enforcement actions and lawsuit settlement amounts, Billings (2008) detects no instance of SEC involvement or monetary penalties for managers of strictly earnings-disclosure-based (as opposed to fraud-based) lawsuits. ${ }^{9}$ If managers become aware of the impending negative news as early as two quarters before, we expect to detect a link between trading in the low-jeopardy window associated with last quarter's earnings announcement (i.e., the "lag green sales" trading window) as well. 
simply remaining quiet, selling shares in the open trading window immediately following the current quarter's earnings announcement, and then waiting for the earnings disappointment to reveal itself next quarter - as opposed to evidence of the more risky approach of selling shares just prior to supplying a warning about next quarter along with this quarter's earnings. Accordingly, our first hypothesis predicts the following relation between managers' disclosure and trading behavior:

\section{H1: When facing earnings disappointment, managers are less likely to supply a preemptive bad news warning about next quarter's earnings as the amount of shares they sell in the two-week trading window following the current quarter's earnings release increases.}

Of course, the cost of silence in the face of impending bad news is not the same for all managers. Accordingly, we anticipate cross-sectional variation in the likelihood that a manager engages in strategic silence. In particular, consistent with the preemption hypothesis in Skinner (1994), we expect that managers of firms operating in high litigation risk environments are less likely to remain silent and, instead, are more likely to preemptively warn. Thus, we predict the following with respect to the disclosure behavior of the managers in high-litigation environments:

\section{H2: When facing earnings disappointment, managers are more likely to supply a preemptive bad news warning about next quarter's earnings when the ex ante likelihood of litigation for the firm is high.}

While the choice to remain silent in the face of impending negative earnings news allows managers to profit by reducing their personal holdings, we expect that this personally opportunistic behavior plays a role in triggering litigation consequences for the firm. Indeed, the findings of Field et al. (2005) suggest that such silence may increase firms' litigation risk. Extant evidence also indicates that litigation risk increases with insider selling (Jones and Weingram 1996, Johnson et al. 2007). Accordingly, we expect that the interaction of the absence of a preemptive warning with the presence of opportunistic selling incrementally 
increases the likelihood that shareholders file lawsuits above the consequences of the individual behaviors. Our third hypothesis predicts the following interactive effect of silence and selling on firms' litigation risk:

\section{H3: The failure to warn interacted with the presence of opportunistic selling prior to the market's receipt of negative earnings news incrementally increases firms' litigation risk.}

If, as we expect, managers' trading behavior and disclosure behavior both play a role in shareholders' decisions to file a lawsuit, this raises the question of whether managers' opportunistic selling completely counteracts any benefit associated with preemptive warning. In our tests of H3, we will examine whether (and, if so, the extent to which) incriminating trading behavior undermines the benefit of timely disclosure.

\section{Data}

In our first analyses, we examine a sample of 107,307 firm-quarter observations from 2001 through 2010. This dataset reflects the intersection of financial statement data available from Compustat, security price data from CRSP, analyst forecast data from I/B/E/S, earnings guidance data from First Call, and insider trading from Thomson Reuters. We obtain the report date of quarterly earnings $(R D Q)$ and earnings for all firm quarters in Compustat. We collect share price, return, shares outstanding and volume data from CRSP and use these data to compute the market value of a firm's equity each quarter (MVE), the 90-day return ending three days prior to the earnings release date (PRIOR_RET), and the standard deviation of returns over that 90-day period (VOLATILITY). We add analyst forecast data from I/B/E/S, using the unadjusted detail file three days prior to each $R D Q$. We calculate the number of analyst forecasts (NUMEST) that are no more than 90 days old (i.e., non-stale), and the standard deviation of these non-stale analyst forecasts (DISPERSION). We measure each quarter's 
surprise (SURPRISE) as reported earnings minus the most recent non-stale median analyst estimate, deflated by stock price three trading days prior to the $R D Q{ }^{10}$

We collect guidance data from First Call’s Company Issued Guidelines ("CIG”) file.

First, we code a variable $(B U N D L E)$ to indicate when a management forecast occurs during the 5 trading days centered on the $R D Q .{ }^{11}$ Next, we distinguish three types of forecast news in our coding: negative (N_FORECAST), positive (P_FORECAST), and confirming (C_FORECAST). Specifically, we code bundled guidance as negative (positive) if management supplies an earnings estimate that falls below (exceeds) the prevailing consensus (i.e., the median analyst forecast) one day before the guidance date. We code the remaining guidance as confirming, capturing cases where management supplies guidance that does not differ from the prevailing consensus. Finally, we also code indicator variables that reflect the firm's recent guidance history. GUIDE_CQTR indicates whether the firm previously provided guidance at any time for the current quarter's earnings. BUNDLE_PRIOR indicates whether the firm bundled earnings guidance with the prior quarter's $R D Q$. To distinguish firms based on a recently demonstrated willingness to use guidance to communicate earnings news to investors, we also code indicator variables that allow us to partition the sample based on firms' histories of recent and committed guidance: RECENT_GUIDER equals one for firms with at least one instance of guidance in the prior 12 quarters, while COMMITTED_GUIDER equals one for firms with at least three instances of guidance in the prior 12 quarters.

The addition of insider trading data obtained from Thomson Reuters' Stock Transactions file represents the final step in the assembly of our dataset. In constructing our quarterly trading

\footnotetext{
${ }^{10}$ Following Rogers and Van Buskirk (2013), we code two indicator variables to reflect the sign of the earnings surprise. P_SURPRISE (N_SURPRISE) equals 1 if SURPRISE for the current quarter exceeds +0.0001 (falls below -0.0001 ). In our multivariate tests, we include the absolute value of surprise (i.e., $|S U R P R I S E|)$ as well as P_SURPRISE and N_SURPRISE.

${ }^{11}$ Our use of a 5-day window follows from prior work (Anilowski, Feng and Skinner 2007). All results remain if we exclude the $3 \%$ of our firm-quarter observations where the guidance does not arrive exactly on the $R D Q$. Further, of the 107,307 firmquarters in our sample, we note 1,932 firm-quarters (1.8\%) where management refrained from bundling negative guidance but then gave non-bundled negative guidance before the subsequent earnings announcement. All results remain if we exclude these firm-quarters from the analysis.
} 
measures, we concentrate on the behavior of directors and officers, consistent with prior work (Johnson, Nelson and Pritchard 2007). This focuses our attention on the trading decisions of insiders who are more likely to be aware of impending negative news and who are also more likely to influence the firms' disclosure decisions. In fact, because we expect the disclosure and trading decisions to be most salient for the $\mathrm{CEO}$ and $\mathrm{CFO}$, we also conduct all of our tests using measures of selling based exclusively on the trades of the CEO and CFO. We measure quarterly selling by insiders (SALES) as the total dollar value of insider sales scaled by beginning quarter $M V E$. We classify sales as opportunistic (SALES_OPP) or routine (SALES_ROU) based on the individual trade-level classification scheme developed in Cohen et al. (2012).

Prior work indicates that the company-level restrictions of insider trading often require insiders to limit their trade to the two weeks immediately following firms' quarterly earnings announcements (Bettis, Coles and Lemmon 2000). Consequently, we measure insider sales over three distinct trading windows during each quarter. As shown in Figure 1, we measure GREEN_SALES as the sales most likely to be allowed under the company's insider trading policy (i.e., the sales that fall in the two-week (10-day trading) period starting after the release of last quarter's earnings). ${ }^{12}$ We measure RED_SALES as the sales least likely to be allowed under the company's insider trading policy (i.e., the sales that take place between current fiscal quarter end $(F Q E)$ and the current quarter's $R D Q)$. YELLOW_SALES capture the sales that take place between the green and the red trading windows.

Panel A of Table 1 provides descriptive statistics for the 107,307 firm-quarter observations in the full sample. Similar to Anilowski, Feng and Skinner (2007), we find that approximately $31 \%(n=32,910)$ of the sample's quarterly earnings announcements coincide with the issuance of guidance $(B U N D L E=1)$. Consistent with the preemption hypothesis in Skinner

\footnotetext{
${ }^{12}$ Results are robust to increasing the GREEN_SALES trading window from 10 to 15 trading days.
} 
(1994), negative forecasts $\left(N_{\_} F O R E C A S T=1\right)$ are more than twice as likely as positive forecasts $\left(P \_F O R E C A S T=1\right)$.

\section{Identifying firm-quarters in which the decision to warn is especially relevant to managers}

As mentioned earlier, we identify the quarters in which the decision to warn versus remain silent should be especially salient for managers. These are the firm-quarters for which managers: (1) face impending negative earnings news, (2) have recently demonstrated a commitment to using guidance to communicate earnings news to investors, and (3) may wish to temper a positive earnings surprise with a cautionary warning about next quarter.

\section{Managers facing impending negative news}

We identify cases where managers face impending negative earnings news by setting an indicator variable (IMPEND_BAD) equal to one if the firm reports disappointing earnings news in the next quarter (i.e., quarter $t+1$ ). We identify the presence of disappointing earnings news based on the issuance of a negative management forecast (i.e., $N \_F O R E C A S T=1$ ) or the reporting of negative earnings news (i.e., $N \_S U R P R I S E=1$ ) in the next quarter. ${ }^{13}$ When we use IMPEND_BAD to partition the full sample, we identify 43,664 firm-quarter observations where managers confront the choice of whether to warn or to remain silent in the current quarter. Panel B of Table 1 supplies descriptive statistics for this subsample. Our earlier evidence from the full sample (see Panel A) provided support for Skinner's hypothesis: managers are more likely to preempt bad news than good news with guidance. Yet, shifting our attention to the subset of observations in which managers face earnings disappointment (see Panel B), we notice that many managers facing impending negative news do not supply a warning, as only $26 \%(11,238 \div$ 43,664 ) bundle a forecast (either quarterly or annual) of negative news for next quarter with the current quarter's earnings announcement. In our tests we examine whether managers' post-

\footnotetext{
${ }^{13}$ Results are robust to measuring disappointing earnings news using a seasonal-random-walk model. Specifically, following Skinner (1994), we define "bad" earnings news as earnings changes less than 5\% of stock price, assuming the seasonal-randomwalk model provides a good approximation for the market's expectation of quarterly earnings.
} 
earnings-announcement selling helps to explain this silence. Because our tests aim to identify the factors associated with the decision to guide in a particular quarter (as opposed to identifying the factors that determine a firm's overall decision to commit to the practice of supplying earnings guidance), we next focus on those instances where managers with a recent history of using guidance to communicate with investors face the decision to warn.

\section{Managers with recent guiding histories facing impending negative news}

Prior literature emphasizes that it is a sustained commitment to disclosure that affects a firm's information environment (Diamond and Verrrecchia 1991; Leuz and Verrecchia 2000; Clinch and Verrecchia 2013). Recent evidence indicates that it is costly to discontinue guidance, as announcements of stoppage are associated with significant drops in share price and assumptions of negative future earnings news by analysts (Houston, Lev and Tucker 2010; Chen, Matsumoto and Rajgopal 2011). Accordingly, we expect that managers who have not guided in the past are less likely to supply a negative news warning in the current quarter. We identify the subset of those IMPEND_BAD observations for which the firm has recently guided (i.e., RECENT_GUIDER = 1) and the subset of those observations where the firm has frequently guided (i.e., COMMITTED_GUIDER $=1$ ) in order to focus on those cases where managers cannot explain away their silence in the current quarter as a general reticence to guide.

As shown in Panel A of Table 2, this process identifies 22,566 firm-quarters in which managers with recent guiding histories face earnings disappointment (i.e., IMPEND_BAD $=1$ and RECENT_GUIDER=1). As expected, the incidence of bundled guidance in the current quarter climbs to $45.9 \%$ in this subsample of recent guiders. Although not tabulated in Panel A, the incidence of current-quarter bundling increases from approximately 50\% (68\%) to $64 \%$ (74\%) for recent (committed) guiders over our sample period. Moreover, as the frequency of bundled guidance in the firm's history increases, the incidence of bundled guidance in the current quarter climbs. As shown in Panel A, when the firm has provided bundled guidance in 
10 to 12 of the prior 12 quarters, the incidence of current-quarter bundling reaches $92.0 \%$. This analysis suggests that our definition of committed guider successfully identifies managers with a real commitment to provide guidance. Indeed, further untabulated analyses suggest that the median committed guider bundles guidance in 8 of the prior 12 quarters (with an interquartile range of 5 to 11 quarters).

Panel B of Table 2 provides descriptive statistics for the subset of 19,166 firm-quarter observations where managers with committed guiding histories face impending negative news (IMPEND_BAD $=1$ and COMMITTED_GUIDER=1). Not surprisingly, this focus on committed guiders has an impact on the incidence of warning. While approximately $74 \%(32,426 \div 43,664)$ of all firms facing impending negative news fail to warn (see Panel B of Table 1), we note that $49 \%(9,449 \div 19,166)$ of committed guiders do the same (see Panel B of Table 2). Though not tabulated, the rate of silence is similar for the recent guider subsample, as $52 \%$ of recent guiders fail to warn. Thus, even among firms with a history of recent and frequent guidance, managers often remain silent when facing earnings disappointment.

Finally, we also examine situations where managers may wish to moderate positive earnings news delivered in the current quarter with guidance that aims to decrease investors' expectations about the firm's performance in the next quarter. We use the presence of a positive earnings surprise in the current quarter (i.e., $P_{-} S U R P R I S E=1$ ) to identify the quarters in which managers have this additional incentive to warn. We find that 13,468 firm-quarter observations involve situations where a recent guider faces impending negative news and delivers positive earnings news in the current quarter. Interestingly, as we narrow our focus to situations where managers have increased incentive to warn, we again find that the proportion of managers remaining silent remains relatively stable. Focusing on managers facing earnings disappointment but supplying positive news in the current quarter, we find (in untabulated analyses) that approximately $51 \%$ of them fail to warn. Moreover, nearly $16 \%$ of these 
managers supply positive forward-looking guidance leading into a disappointing quarter. In our multivariate tests, we exploit cross-sectional variation in bundled forecast news to examine whether post-announcement selling helps to explain the quarters in which managers remain silent or use guidance to communicate earnings news to investors.

\section{Intra-quarter insider selling}

As described earlier, our quarterly measures of insider sales identify trade that is more likely $(R E D)$, less likely (YELLOW), and least likely (GREEN) to be restricted by firms' insider trading regulations. Consistent with Bettis, Coles and Lemmon (2000), Huddart, Ke and Shi (2007), Table 3 reports evidence that a disproportionate amount of selling takes place in the GREEN trading window after the $R D Q$. In particular, as shown in both Panel A (for the full sample) and Panel B (for the impending negative news subsample), while the GREEN window comprises only $16 \%$ of the quarter, $36 \%$ of the quarter's total insider selling (based on dollar value) occurs in the window. In contrast, while the $R E D$ window comprises $30 \%$ of the quarter, only $9 \%$ of the quarter's total selling occurs in the window.

Acknowledging the fact that not all insider trading is motivated by a desire to exploit information asymmetries, Cohen, Malloy and Pomorski (2012) develop a classification scheme that distinguishes "routine" insider trades from "opportunistic" insider trades. ${ }^{14}$ Consequently, we use Cohen et al.'s individual trade-level classification scheme to separately identify routine (“SALES_ROU”) and opportunistic (“SALES_OPP”) sales. Given that Cohen et al.'s classification scheme is based on the frequency of trades executed by an insider in a particular month in his/her history, it is not surprising that very few "red-window" sales are classified as

\footnotetext{
${ }^{14}$ In particular, Cohen et al. (2012) develop a classification scheme that distinguishes "routine" insider trades from "opportunistic" insider trades based on the past history of trades (i.e., the pattern and timing of trades in the insider's recent history). Cohen et al. corroborate their approach to partitioning trades by documenting that the trades flagged as "opportunistic" are powerful predictors of future firm returns, news and events, but that the "routine" trades have no predictive powers.
} 
routine. In untabulated analyses, we document very similar trading patterns for our other subsamples.

We next examine the relation between insider selling and strategic silence. Figure 1 depicts the firm-quarter setup that we use to address the research question: Does insider selling explain managers' decision to remain silent in the face of impending earnings disappointment?

\section{Selling and the decision to remain silent}

\section{Selling and the likelihood of a bundled forecast}

H1 predicts that managers facing impending earnings disappointment are less likely to preemptively warn if they plan to trade to exploit this knowledge. To test this hypothesis, we estimate the following logistic regression model based on Rogers and Van Buskirk (2013):

$$
\begin{aligned}
& \text { N_FORECAST } T_{i, t}=\alpha_{0}+\alpha_{1}\left(\text { GUIDE_CQTR }_{i, t}\right)+\alpha_{2}\left(\text { BUNDLE_PRIOR }_{i, t}\right)
\end{aligned}
$$

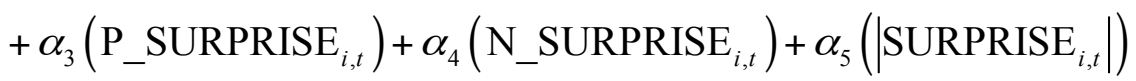

$$
\begin{aligned}
& +\alpha_{6}\left(\operatorname{LOSS}_{i, t}\right)+\alpha_{7}\left(\text { DISPERSION }_{i, t}\right)+\alpha_{8}\left(\text { PRIOR_RET }{ }_{i, t}\right) \\
& +\alpha_{9}\left(\mathrm{LOG}_{-} \mathrm{MVE}_{i, t}\right)+\alpha_{10}\left(\mathrm{LOG}_{-} \mathrm{NUMEST}_{i, t}\right)+\alpha_{11}\left(\mathrm{PROPMB}_{i, t}\right) \\
& +\alpha_{12}\left(\text { VOLATILITY }_{i, t}\right)+\alpha_{13}\left(\text { LITIGATION RISK }_{i, t}\right)+\alpha_{14}\left(\operatorname{SALES}_{i, t}\right)+\varepsilon_{i, t} \text {. }
\end{aligned}
$$

The presence of negative guidance bundled with the current quarter's earnings announcement (i.e., $N \_F O R E C A S T=1$ ) serves as the dependent variable. Consistent with Rogers and Van Buskirk (2013), we predict that the likelihood of current-quarter guidance increases with past guidance. Accordingly, the inclusion of both GUIDE_CQTR and BUNDLE_PRIOR allows us to focus on the factors associated with the decision to guide in the current quarter - as opposed to examining the factors that determine firms' decisions to commit to an overall practice of issuing guidance. ${ }^{15}$ Following Rogers and Van Buskirk (2013) we also control for the current quarter's

\footnotetext{
${ }^{15}$ Not surprisingly, BUNDLE_PRIOR and GUIDE_CQTR are highly correlated (61\% Spearman correlation in the full sample of firm-quarter observations and $38 \%$ Spearman correlation in the subsample of firm-quarter observations for recent guiders).
} 
earnings news (P_SURPRISE, $N \_S U R P R I S E$, |SURPRISE $\mid$, and LOSS), the information environment of the firm (DISPERSION, LOG_NUMEST, LOG_MVE), and recent performance (PRIOR_RET). Following Billings et al. (2014), we also control for forecast difficulty with the inclusion of the level of stock return volatility (VOLATILITY).

The inclusion of LITIGATION RISK (i.e., the ex ante probability estimate of the likelihood that the firm will be subject to $10 \mathrm{~b}-5$ litigation in the next quarter) and SALES in Equation (1) allows us to test our first and second hypotheses. ${ }^{16}$ Consistent with the preemption hypothesis in Skinner (1994), H2 predicts that managers facing higher ex ante litigation risk are more likely to warn in the face of impending negative news and, accordingly, we predict a positive coefficient for LITIGATION RISK.

H1 predicts a negative coefficient for SALES: selling is associated with a decreased likelihood of negative earnings warnings (i.e., an increased likelihood of remaining silent). As mentioned earlier, we expect trading restrictions to influence managers' selling patterns. Consequently, we expect that the decision to remain silent will link to insider selling that is concentrated in the low-jeopardy, typically open trading window following the announcement of the current quarter's earnings. Thus, we predict a negative coefficient for GREEN_SALES. If managers are aware of the impending negative news earlier, we also expect sales in the prior quarter's open trading window (i.e., $L A G \_G R E E N \_S A L E S$ ) to exhibit a negative coefficient.

Panel A of Table 4 reports the results of estimating Equation (1) for the full sample (in column [1]) and successive subsamples with impending bad news (column [2]), with recent guidance histories (column [3]), with committed guiding histories (column [4]), and reporting

Following Rogers and Van Buskirk (2013) we include both in our tabulated regressions. All of our results remain when we reestimate our regressions excluding either BUNDLE_PRIOR or GUIDE_CQTR.

${ }^{16}$ As described in Appendix A, we estimate a quarterly measure of ex ante litigation risk following the model developed by Kim and Skinner (2012). 
positive earnings news in the current quarter (column [5]). In column [6], we further narrow our focus by using the trades of only the CEO and CFO. In all cases, we find support for H1: the coefficients on GREEN_SALES and LAG_GREEN_SALES are significantly negative. ${ }^{17}$

Consistent with legal fears constraining opportunism (i.e., H2), we also find that managers are more likely to warn of negative news as ex ante litigation risk increases, as evidenced by the positive coefficient for LITIGATION RISK in Panel A. This suggests that managers who disappoint investors with negative earnings news next quarter are less likely to bundle forwardlooking negative earnings guidance with the current quarter's earnings news as the number of shares they sell increases. Yet, in the presence of increased litigation risk, managers are less likely to keep quiet. Further, as we narrow our focus to the managers for whom the decision to warn versus stay silent is most salient (i.e., moving from column [1] to column [6]), we find that the mean marginal effect on GREEN_SALES increases. In fact, limiting analysis to CEO/CFO trades only in column [6], our evidence indicates that when these insiders increase their greenwindow sales by $1 \%$ of $M V E$, the likelihood of a preemptive warning declines by $3.37 \%{ }^{18}$

The results presented in Panel B provide additional evidence that the silence we observe is strategically motivated. In this panel, we re-estimate Equation (1) but this time predict the presence of a positive bundled forecast (i.e., $P_{-} F O R E C A S T=1$ ). In contrast to evidence linking the failure to warn with increased selling, we find that managers are more likely to bundle positive earnings guidance $\left(P_{-} F O R E C A S T=1\right)$ with the current quarter's earnings news as the

\footnotetext{
${ }^{17}$ The significance of both coefficients supports H1, as this indicates that selling prior to the market's receipt of the disappointing earnings news is associated with a failure to warn. The larger (i.e., more negative) coefficient for GREEN_SALES is consistent with the notion that managers are more likely to be aware of the negative news as of the current quarter's $R D Q$ as opposed to as of the prior quarter's $R D Q$. If managers are not aware of the impending disappointment, they do not have an incentive to sell.

${ }^{18}$ In untabulated results, we re-estimate all regression equations with the inclusion of the contemporaneous YELLOW_SALES and $R E D \_S A L E S$ variables. In all specifications, we detect no relation between RED_SALES and the decision to warn of impending negative news and we find limited evidence of a negative relation between YELLOW_SALES and the decision to warn (with 2 of the 6 specifications detecting significance at the 0.10 level). In our tabulated analyses, we focus on GREEN_SALES as these sales take place immediately after the disclosure decision is made and are also made within the low jeopardy trading window.
} 
amount of shares sold in the green window increases. ${ }^{19}$ Again, we notice that the mean marginal effect grows as we narrow our focus to the observations in which the decision to warn is most relevant. Hence, insider selling is not associated with a general unwillingness to use guidance to communicate with investors (i.e., managers who trade are not always more likely to remain silent). Rather, the desire to sell shares appears to play a role in managers' selective/tactical silence. As such, the combined evidence suggests that managers' quarterly disclosure decisions contain elements of subtle opportunism. Again consistent with Skinner (1994), LITIGATION RISK enters the later regressions (i.e., those in Panel B) with the opposite coefficient. That is, managers are less likely to deliver a positive/confirming forecast as ex ante litigation risk increases. Further, the increased magnitude of the coefficient in these regressions (as compared to those in Panel A) suggests that managers who are fearful of litigation are especially hesitant to supply positive news to investors.

As discussed earlier, because it is not possible to cleanly identify the point at which managers learn of earnings news, our approach to measuring impending negative news categorizes managers of all firms that report negative earnings news next quarter as possessing this knowledge in the current quarter. The measurement error associated with this approach likely reduces our ability to detect significant relations in the data, as the trading behavior of managers who are unaware of impending negative news should not help to predict whether they warn of this yet-to-be-known news. Nonetheless, if a manager's ability to forecast the firm's future earnings is associated with unobserved firm characteristics that correlate in some way with insider sales, then this could potentially explain the observed link between disclosure and selling. The fact that our results in Panels A and B of Table 4 hold when we narrow our focus to the

\footnotetext{
${ }^{19}$ Focusing on management forecasts that confirm current earnings expectations (i.e., C_FORECAST $=1$ ), in untabulated analyses we detect no significant relation between managers' selling behavior and the decision to supply a forecast. We do, however, find that the likelihood of supplying a confirming forecast decreases with ex ante litigation risk.
} 
disclosure decisions of committed guiders suggests that a firm's general willingness/ability to guide does not explain our findings.

To further address this concern, Panel $\mathrm{C}$ of Table 4 replicates the analyses in Panels A and B but limits attention to the 11,716 firm-quarters in which committed guiders who recently bundled — in both the same quarter of last year and in the prior quarter (i.e., BUNDLE_SQLY=1 and $B U N D L E \_P R I O R=1$ ) — face the decision to warn of impending negative news. This allows our tests to focus on explaining the quarters in which committed guiders do or do not warn as opposed to explaining whether the firm is a guider or not. In so doing, it further addresses any concern that unobserved firm characteristics explain the inability/failure to warn, as these firms routinely provide guidance. Indeed, untabulated analyses indicate that the mean (median) committed guider that bundled in both the prior quarter and in the same quarter of last year bundled in 9.9 (11) of the prior 12 quarters. As shown in all specifications of Panel C, all of our results remain. That is, insider selling helps to predict the quarters in which a firm that guides the overwhelming majority of the time remains silent. And, as in our earlier regressions in Panel B, we again find that the relations reverse when we shift to predicting positive guidance (i.e., $P_{-}$FORECAST) in the last two specifications. Consequently, this mitigates any concern that our earlier evidence merely reflects unobserved firm traits that correlate with a firm's willingness and ability to guide.

\section{Opportunistic selling}

In Table 5 we repeat our previous analysis using Cohen et al.'s individual trade-level classification scheme to separately identify routine ("ROU”) and opportunistic ("OPP”) trades. For brevity, we do not tabulate the control variables. As in Table 4, Panel A reports the prediction of negative guidance ( $\left.N_{-} F O R E C A S T\right)$, while Panel B reports the prediction of 
positive guidance ( $P_{-}$FORECAST). Consistent with the notion that managers' failure to warn is strategically motivated, we find that the failure to warn links to opportunistic, as opposed to routine, trade: SALES_OPP are associated with a decreased (increased) likelihood of delivering a negative (positive) news warning in the face of impending earnings disappointment. This result remains/strengthens when we limit analysis to the firm-quarters in which frequent guiders deliver disappointing earnings news next quarter in contrast to positive current-quarter earnings news and when we limit analysis to the trades of the CEO and CFO (columns [2] through [6]). Morever, routine sales in the green window are never significantly associated with the decision to warn. Again, we notice the expected contrasting signs for LITIGATION RISK: managers are more (less) likely to give a negative (positive) news forecast as ex ante risk of punishment increases.

In summary, the observed relation between silence and selling strengthens when we limit attention to the quarterly observations for which the decision to warn versus trade is most relevant and when we narrow our focus to measures of opportunistic trade by just the CEO and CFO. Further, when we shift our attention to the likelihood that managers deliver a positive forecast with the current quarter's earnings announcement, we see just the opposite: opportunistic selling is associated with increased likelihood of disclosure. Yet, we notice a reticence to engage in opportunistic disclosure as ex ante litigation risk increases.

Combined, this evidence indicates that trading incentives help to explain why some managers strategically remain silent even though legal liability may provide incentive for them to bundle a warning with the current quarter's earnings announcement. These results contribute to the literature examining managers' incentives to correct information asymmetries via negative news warnings as well as the literature examining insiders' exploitation of information 
asymmetries. Absent direct examination of trading-based hypotheses, studies often exclude trading considerations when modeling managers' guidance decisions. These findings underscore the importance of considering the interplay between managers' disclosure and trading behavior when studying the costs and benefits associated with disclosure. In the next section, we examine how the combined behavior of silence and selling links to litigation risk.

\section{Selling, silence and litigation risk}

Field, Lowry and Shu (2005) (hereafter "FLS") address the question of whether earnings warnings effectively deter (as opposed to trigger) litigation. In so doing, they demonstrate an important endogeneity at play in this setting: firms with higher litigation risk are more likely to issue a warning in the face of earnings disappointment. Accordingly, using a simultaneousequations framework to account for this endogenous relation between disclosure and litigation, FLS find no evidence that warnings trigger litigation and, in fact (as discussed earlier), they find weak evidence that preemptive disclosure lowers firms' risk of being sued. Our earlier analyses, however, indicate that the managers who are more likely to warn in the face of impending bad news are also more likely to refrain from engaging in opportunistic insider selling.

Consequently, this raises the question of whether the absence of opportunistic selling, as opposed to the presence of a preemptive warning, lowers firms' litigation risk, as insider trading is not considered in FLS.

\section{Lawsuit and propensity-matched control sample}

To investigate whether trading behavior interacts with disclosure behavior to influence firms' litigation risk, we first replicate the analyses of FLS and then adjust their tests in order to consider the interplay between disclosure and trade. Although we follow the simultaneousequations framework of FLS, we make adjustments to their methodology in an effort to take 
advantage of recent advances in both approaches to the selection of control samples (i.e., we make use of a propensity-matching approach) and the measurement of litigation risk (i.e., we employ the litigation risk model of Kim and Skinner (2012)).

We begin by assembling a sample of firms that faced earnings-related litigation from 2002 through 2012 using lawsuit data obtained from Stanford Law School's Securities Class Action Clearinghouse (http://securities.stanford.edu). Because prior research suggests that firm size, industry membership and recent performance play critical roles in the decision to file lawsuits (Johnson et al. 2007) and the evidence in FLS suggest that those same factors also determine firms' disclosure decisions, we assemble a propensity-matched sample of control firms that faced similar litigation risk during this same time frame following the litigation risk model supplied in Equation (3) of Kim and Skinner (2012). As detailed in Kim and Skinner (2012), the litigation risk model takes into account industry membership, firm size, performance (both return and sales growth), skewness of returns, volatility, and share turnover, which are also variables known to influence firms' disclosure decisions. ${ }^{20}$

Panel A of Table 6 provides descriptive statistics for these 478 lawsuit $(S U E D=1)$ and 478 control $(S U E D=0)$ firms. As evidenced by the lack of significant mean or median differences, our propensity-matching approach leads us to identify a suitable group of similarly situated control firms in terms of industry membership (TECHNOLOGY, RETAIL, REGULATED or FPS), firm size (MVE), return skewness (SKEWNESS), and recent growth in sales (SALES GROWTH). Nonetheless, some important differences remain. While we detect no differences in means, we do observe significantly lower median return performance (RETURN) and higher median share turnover when we compare the SUED firm to the NON-SUED firm. In our upcoming multivariate tests, we address these lingering disparities with the inclusion of additional control variables.

\footnotetext{
${ }^{20}$ Please refer to Appendix B for detailed variable definitions.
} 
Shifting attention to our variables of interest, we detect significant mean and median differences when comparing both the disclosure and trading behavior of the SUED firms to that of the NON-SUED firms. Consistent with Francis et al. (1994) and Skinner (1997) as well as FLS, we find that managers of SUED firms are more likely to warn in the face of earnings disappointment. This reflects the endogeneity between the likelihood of warning and litigation risk that FLS highlight. We, however, also notice that managers of SUED firms tend to have sold more shares in the period prior to the market's receipt of the disappointing earnings news. In our upcoming multivariate tests, we will explore the extent to which this potentially opportunistic trading behavior undermines or dominates any potential benefits associated with preemptive warnings.

\section{Replication of Field, Lowry and Shu (2005): Does disclosure deter litigation?}

We begin our analyses by replicating the FLS findings in our sample. To do so, we start by confirming a link between litigation risk and earnings warnings using their initial single-stage approach. In particular, we estimate the following logistic regression (firm subscripts omitted):

$$
\begin{aligned}
& \text { WARN }=\beta_{0}+\beta_{1}(\log \text { MVE })+\beta_{2}(\text { TECHNOLOGY })+\beta_{3}(\text { REGULATED }) \\
& +\beta_{4}(\text { RETAIL })+\beta_{5}(\text { RETURN })+\beta_{6}(\text { VOLATILITY })+\beta_{7}(\text { TURNOVER }) \\
& +\beta_{8}(\text { PRIOR DISCLOSURE })+\beta_{9}(\text { SUED })+\varepsilon .
\end{aligned}
$$

As shown in column [1] of Table 7, we detect a significantly positive coefficient for SUED, which aligns with the results presented in FLS (see their Table 3). After establishing this initial link, we move on to test for a link between disclosure and litigation risk again using their initial single-stage approach. In particular, we estimate the following logistic regression:

$$
\begin{aligned}
& \text { SUED }=\gamma_{0}+\gamma_{1}(\log \text { MVE })+\gamma_{2}(\text { TECHNOLOGY })+\gamma_{3}(\text { REGULATED }) \\
& +\gamma_{4}(\text { RETAIL })+\gamma_{5}(\text { RETURN })+\gamma_{6}(\text { VOLATILITY })+\gamma_{7}(\text { TURNOVER }) \\
& +\gamma_{8}(\text { WARN })+\varepsilon .
\end{aligned}
$$


As shown in column [2] of Table 6, we detect a significantly positive coefficient for $W A R N$, which again aligns with results presented in FLS (see their Table 4). Thus, the evidence presented in columns [1] and [2] of Table 7, indicates that the endogeneity between disclosure and litigation is present in our sample as well. In other words, like FLS, we find that the likelihood of preemptive warning increases with litigation risk and, absent efforts to address this endogeneity, the presence of a warning then appears to increase a firm's litigation risk.

Building on these initial findings, we next adjust our regression framework to consider the endogenous relation between disclosure and litigation, again following FLS. In particular, we estimate the following system of equations:

$$
\begin{aligned}
& \text { WARN }=\delta_{0}+\delta_{1}(\log \text { MVE })+\delta_{2}(\text { TECHNOLOGY })+\delta_{3}(\text { REGULATED }) \\
& +\delta_{4}(\text { RETAIL })+\delta_{5}(\text { RETURN })+\delta_{6}(\text { VOLATILITY })+\delta_{7}(\text { TURNOVER }) \\
& +\delta_{8}(\text { PRIOR DISCLOSURE })+\varepsilon . \\
& \text { SUED }=\theta_{0}+\theta_{1}(\log \text { MVE })+\theta_{2}(\text { TECHNOLOGY })+\theta_{3}(\text { REGULATED }) \\
& \quad+\theta_{4}(\text { RETAIL })+\theta_{5}(\text { RETURN })+\theta_{6}(\text { VOLATILITY })+\theta_{7}(\text { TURNOVER }) \\
& +\theta_{8}(\text { WARN INSTRUMENT })+\varepsilon .
\end{aligned}
$$

Columns [3] and [4] of Table 7 present results using the full sample of lawsuit and control firms; Columns [5] and [6] of Table 7 limit analysis to non-dismissed lawsuits (and the associated control firms). Consistent with the presence of a deterrence effect associated with preemptive warning, we detect a significantly negative coefficient for the $W A R N$ instrument, as shown in the second-stage SUED regression results presented in Specifications [4] and [6] of Table 7. FLS report these same regressions (see their Table 4 for the full sample results; see their Table 5 for the results based on the sample that excludes dismissed lawsuits). In contrast to the somewhat weak evidence in FLS, we find strong evidence of a deterrence effect. That is, using the simultaneous-equations framework introduced by FLS, our evidence indicates that preemptive warning is associated with reduced litigation risk across all specifications. 
Next, we investigate whether managers' opportunistic selling behavior (which our earlier analyses show is associated with the decision to remain silent in the face of earnings disappointments) explains the increased rate of litigation associated with the failure to warn. Does disclosure deter litigation when managers' trading behavior is considered?

To test whether managers' trading behavior neutralizes or even reverses the litigation benefit associated with preemptive warnings, we introduce measures of insider selling to the simultaneous-equation framework of FLS. Specifically, we estimate the following revised system of equations:

$$
\begin{aligned}
& \text { WARN }=\delta_{0}+\delta_{1}(\text { Log MVE })+\delta_{2}(\text { TECHNOLOGY })+\delta_{3}(\text { REGULATED }) \\
& +\delta_{4}(\text { RETAIL })+\delta_{5}(\text { RETURN })+\delta_{6}(\text { VOLATILITY })+\delta_{7}(\text { TURNOVER }) \\
& +\delta_{8}(\text { PRIOR DISCLOSURE })+\delta_{9}(\text { SALES })+\varepsilon . \\
& \text { SUED }=\theta_{0}+\theta_{1}(\text { Log MVE })+\theta_{2}(\text { TECHNOLOGY })+\theta_{3}(\text { REGULATED }) \\
& +\theta_{4}(\text { RETAIL })+\theta_{5}(\text { RETURN })+\theta_{6}(\text { VOLATILITY })+\theta_{7}(\text { TURNOVER }) \\
& +\theta_{8}(\text { SILENCE })+\theta_{9}(\text { SALES })+\theta_{10}(\text { SILENCE } * \text { SALES })+\varepsilon .
\end{aligned}
$$

Equation (6) adds trading behavior (SALES) to the first-stage FLS regression. We measure SALES as the total dollar value of insider sales during the class period (scaled by the market value of equity). ${ }^{21}$ To focus attention to the opportunism associated with the combined behavior of silence (i.e., the failure to warn) and selling in the face of impending earnings disappointment, we reverse the first-stage regression to focus on the prediction of silence (i.e., $W A R N=0$ ) in order to obtain the predicted value to use in Equation (7). Using this predicted value of SILENCE obtained from the estimation of Equation (6), we test $\mathrm{H} 3$ with the inclusion of the interaction of SILENCE and SALES in Equation (7).

\footnotetext{
${ }^{21}$ Our earlier analyses adjust the measurement of insider sales to take into account that managers likely alter their trading patterns in response to firm-level insider trading restrictions. In these litigation risk analyses, however, we expect that the presence of insider selling, regardless of its timing within the quarter, will be used by plaintiffs' attorneys as evidence of delayed disclosure. Consequently, we do not distinguish between RED-, YELLOW-, and GREEN-window trading in these analyses.
} 
We present the results of the second-stage regressions in Table $8 .^{22}$ Column [1] replicates the basic FLS result from columns [3] and [4] of Table 7, but with the prediction of SILENCE (as opposed to WARN) in the first-stage. Columns [2] through [5] introduce various measures of insider selling to the analysis. In particular, columns [2] through [4] measure sales using the length of the class period as the trading window, with column [3] focusing on CEO and CFO trades only and column [4] classifying trades as routine ("SALES_ROU”) or opportunistic ("SALES_OPP"). Following Johnson, Nelson and Pritchard (2007), column [5] focuses on abnormal trading during the class period, measuring abnormal sales (SALES_AB) as the difference in shares traded during the class period and the equivalent length of time immediately prior to the beginning of the class period, scaled by shares outstanding. Finally, column [6] includes an indicator variable $(G O O D)$ set equal to one if the firm supplied a good news forecast at any point during the class period prior to either the delivery of a bad news warning or the end of the class period.

As shown in Table 8, we find that SILENCE is associated with increased litigation risk across all specifications, which suggests that the deterrence effect of warning remains even after we introduce $S A L E S$ to the analysis. Further, as expected, $S A L E S$ are also positively related to the likelihood of a lawsuit. Thus, this evidence suggests that disclosure deters and trading triggers lawsuit filings. More important, consistent with H3, we detect a significantly positive coefficient for the interaction term $(S A L E S * S I L E N C E)$ across all specifications. Accordingly, this evidence indicates that the absence of a warning combined with the presence of selling exacerbates the consequences associated with the individual behaviors. As expected, the relations strengthen when we narrow our focus to the trades of CEOs and CFOs (column [3]).

\footnotetext{
${ }^{22}$ For brevity, we do not tabulate the first-stage regression, but all results align with expectations. Further, the introduction of trading considerations results in improvements in the fit of the model, as both the Pseudo $\mathrm{R}^{2}$ and ROC area exhibit statistically significant improvement (based on log-likelihood tests) in all specifications.
} 
Further, the relations remain when we focus on opportunistic selling (column [4]) or abnormal selling (column [5]) behavior in the class period. In addition to suggesting that there is a disclosure benefit associated with bad news warnings, Skinner (1994) indicates that managers will be held accountable for their inaccurate good news forecasts. Consistent with this expectation, in column [6] we find that the presence of a good news forecast at any point during the class period but prior to the delivery of bad news (i.e., $G O O D=1$ ) is associated with increased litigation risk. Moreover, a good news forecast combined with the absence of a warning (i.e., predicted silence) is associated with yet higher rates of litigation.

Although the results thus far provide strong support for $\mathrm{H} 3$, an alternative explanation for our findings is that insiders of firms with worse performance prospects are more likely to sell their holdings and this poor performance links to increased litigation risk. That is, poor expected future performance drives both insider sales and future litigation risk. First, given the incentives of plaintiffs and their lawyers, we expect that the presence of insider selling makes it easier for plaintiffs to assert intentional misconduct by managers. Consistent with this expectation of a main effect of sales, prior literature (e.g., Johnson et al. 2007) documents a link between insider selling and litigation risk. Second, examining the correlations (untabulated) between our insider selling variables and future performance (as measured by the 3-day return surrounding the end of the class period), we find no evidence that insider sales correlate with future performance. Yet, we do find that returns during the class period are negatively correlated with insider sales, suggesting that insiders are less likely to sell when returns are higher. Following FLS, we control for this return but in the analysis in Table 8 we extend the return to include the 3-day return surrounding the end of the class period. ${ }^{23}$ Finally, in untabulated analyses, we also re-

\footnotetext{
${ }^{23}$ The inclusion of the extended return as well as the introduction of trading considerations results in statistically significant increases in the $\mathrm{R}^{2}$ and ROC of the model. In particular, the $\mathrm{R}^{2}$ climbs from $2.4 \%$ (see column [4] of Table 7) to $20.0 \%$ (see column [1] of Panel A of Table 8), while the ROC increases from 0.591 to 0.790 across the two specifications. In untabulated analyses, we find that the majority of the increase stems from the inclusion of the extended return, although the increase attributable to trading considerations is also statistically significant.
} 
estimate our simultaneous-equations framework with an added initial stage that allows trading, disclosure and litigation risk to be jointly determined. In particular, following the model supplied in Cheng and Lo (2006), we obtain an estimate of unexpected sales and use this abnormal measure of sales in our disclosure (i.e., Equation (6)) and litigation risk (i.e., Equation (7)) regressions. All of our results are robust to this alternative specification.

\section{Does trading offset the benefit associated with warning?}

Given the evidence presented in Panel A of Table 8, it appears that managers' trading behavior and disclosure behavior combine to play a role in shareholders' decisions to file a lawsuit. Yet, the question of whether managers' opportunistic selling completely counteracts the benefit associated with preemptive warning remains. Shifting our attention back to the prediction of $W A R N$ in the first-stage allows our interaction term (i.e., $S A L E S * W A R N$ ) to address this question directly. Accordingly, we present these abbreviated second-stage results in Panel B of Table 8. The coefficient of -2.552 for $W A R N$ along with the -57.742 coefficient for the interaction of $S A L E S * W A R N$ suggests that the presence of opportunistic trade rarely, if ever, completely offsets the benefit associated with disclosure. Indeed, the magnitudes of these coefficients indicate that insiders would need to sell approximately $10 \%$ of the firm's market value in the class period in order to completely cancel out the benefit associated with preemptive warnings. Based upon these point estimates, we find that insider selling rarely reaches sufficient magnitude to offset the suggested benefit associated with disclosure. In our litigation sample, the extreme values of SALES are sales of $5.2 \%$ and $16.5 \%$ of $M V E$ for the $95^{\text {th }}$ and $99^{\text {th }}$ percentiles.

In summary, the combined behavior of silence and selling in the face of impending earnings disappointment appears to incrementally raise firms' litigation risk above and beyond the individual effects. At the same time, the evidence indicates that selling prior to the delivery of bad news warning generally offsets some, but not all, of the disclosure benefit of a warning. 
Thus, even with the addition of incriminating selling behavior, a preemptive warning provides some protection against litigation.

\section{Conclusion}

Despite potential disclosure benefits, many managers fail to warn prior to an earnings disappointment, even when they have guided in the recent past. In this paper, we provide evidence that insider trading helps to explain this silence. This relation between silence and selling in the face of bad news strengthens when we narrow our focus to opportunistic selling and when we limit attention to firms with a recent history of supplying guidance. Thus, the evidence indicates that trading incentives help to explain whether managers choose to guide in a particular quarter. These findings also suggest that managers rely on a subtle form of opportunism in order to exploit information asymmetries — simply remaining quiet, selling shares in this quarter's open trading window, and then waiting for the earnings disappointment to reveal itself next quarter-as opposed to engaging in an overtly opportunistic approach of selling shares just prior to supplying a warning about next quarter along with this quarter's earnings.

These results raise the question of whether the absence of incriminating trading behavior, as opposed to the presence of a cautionary warning, drives the observed reduction in litigation risk potentially attributed to disclosure. Examining a sample of firms that experienced earningsrelated lawsuit filings, we find that silence and selling both independently increase firms' litigation risk. More important, our evidence indicates that the interaction of silence and selling incrementally raises firms' litigation risk beyond the individual effects. At the same time, the evidence suggests that opportunistic selling prior to the delivery of bad news offsets some, but not all, of a warning's benefit for virtually all of the firms in our litigation sample. Thus, we provide robust evidence that warning reduces litigation risk. 
The effectiveness of U.S. securities litigation in punishing opportunistic behavior is hotly debated, with some influential legal scholars concluding that the majority of lawsuits reflect frivolous actions that unfairly target "deep pocket" defendants and confuse legitimate volatility with corporate wrongdoing (Alexander 1991, Grundfest 1994, 1995, Seligman 1994, Helland 2006, Choi 2007, Johnson et al. 2007, Choi et al. 2009). Our study informs this ongoing debate. In contrast to studies that question whether the merits play any substantial role in triggering litigation, our evidence indicates that meritorious factors are important drivers of lawsuit filings. Indeed, our findings suggest that "good" disclosers (i.e. voluntary warners) enjoy a reduced risk of litigation, while litigation emerges to punish strategic silence, opportunistic selling and the incriminating interaction of the two behaviors. Collectively, our findings underscore the conflict between manager-level trading incentives and firm-level disclosure incentives: strategic silence interacts with opportunistic selling by managers to increase the litigation consequences borne by the firm. 


\section{References}

Alexander, J. 1991. Do the merits matter? A study of settlements in securities class actions. Stanford Law Review 43, 497-598.

Anilowski, C., M. Feng, and D. Skinner. 2007. Does earnings guidance affect market returns? The nature and information content of aggregate earnings guidance. Journal of Accounting and Economics 44, p. 36-63.

Bettis, J., J. Coles, and M. Lemmon. 2000. Corporate policies restricting trading by insiders. Journal of Financial Economics 57: 191-220.

Billings, M. 2008. Disclosure timeliness, insider trading opportunities and litigation consequences. Working paper.

Billings, M., R., Jennings, and B. Lev. 2014. On guidance and volatility. Working paper.

Chen, S., D. Matsumoto, and S. Rajgopal. 2011. Is silence golden? An empirical analysis of firms that stop giving quarterly earnings guidance. Journal of Accounting and Economics 51, p. 134-150.

Cheng, Q. and K. Lo. 2006. Insider trading and voluntary disclosures. Journal of Accounting Research 44: 815-848.

Choi, S. 2007. Do the merits matter less after the Private Securities Litigation Reform Act? Journal of Law, Economics and Organization 23, 598-626.

Choi, S., K. Nelson, and C. Pritchard. 2009. The screening effect of the Private Securities Litigation Reform Act. Journal of Empirical Legal Studies 6: 35-68.

Clinch, G. and R. Verrecchia. 2013. Voluntary disclosure and the cost of capital. Working paper.

Cohen, L., C. Malloy, and L. Pomorski. 2012. Decoding inside information. Journal of Finance 67: 1009-1043.

Desai, H., C. Hogan, and M. Wilkins. 2006. The reputational penalty for aggressive accounting: earnings restatements and management turnover. The Accounting Review 81: 83-112.

Diamond, D. and R. Verrecchia. 1991. Disclosure, liquidity, and the cost of capital. Journal of Finance 46, 1325-1359.

Field, L., M. Lowry, and S. Shu. 2005. Does disclosure deter or trigger litigation? Journal of Accounting and Economics 39: 487-507.

Francis, J., D. Philbrick, and K. Schipper. 1994. Shareholder litigation and corporate disclosures. Journal of Accounting Research 32: 137-164. 
Grundfest, J. 1994. Disimplying private rights of action under the federal securities laws: The commission's authority. Harvard Law Review 107: 963-1024.

Grundfest, J. 1995. Why disimply? Harvard Law Review 108: 727-747.

Healy, P. and K. Palepu. 2001. Information asymmetry, corporate disclosure, and the capital markets: a review of the empirical disclosure literature. Journal of Accounting and Economics $31,405-440$.

Helland, E. 2006. Reputational penalties and the merits of class-action securities litigation. Journal of Law and Economics 49, 365-395.

Houston, J., B. Lev, and J. Tucker. 2010. To guide or not to guide? Causes and consequences of stopping quarterly earnings guidance. Contemporary Accounting Research 27, 143-185.

Huddart, S., B. Ke, and C. Shi. 2007. Jeopardy, non-public information, and insider trading around SEC 10-K and 10-Q filings. Journal of Accounting and Economics 43: 3-36.

Hugon, A. and Y. Lee. 2014. Do trading plans allow insiders to profit from foreknowledge of earnings results? Working paper.

Jagolinzer, A. 2009. SEC Rule 10b5-1 and insiders' strategic trade. Management Science 55: 224-239.

John, K. and L. Lang. 1991. Strategic insider trading around dividend announcements: theory and evidence. Journal of Finance 46: 1361-1398.

Johnson, M., K. Nelson, and A. Pritchard. 2007. Do the merits matter more? The impact of the Private Securities Litigation Reform Act. Journal of Law, Economics, and Organization 23: $627-652$.

Jones, C. and S. Weingram. 1996. The determinants of 10b-5 litigation risk. Working paper.

Karpoff, J. and D. Lee. 1991. Insider trading before new issue announcements. Financial Managerment 20: 18-26.

Ke, B., S. Huddart, and K. Petroni. 2003. What insiders know about future earnings and how they use it: evidence from insider trades. Journal of Accounting and Economics 35: 315-346.

Kim, I. and D. Skinner. 2012. Measuring securities litigation risk. Journal of Accounting and Economics 53: 290-310.

Lee, D., W. Mikkelson, and M. Partch. 1992. Managers' trading around stock repurchases. Journal of Finance 47: 1947-1961. 
Leuz, C. and R. Verrecchia. 2000. The economic consequences of increased disclosure. Journal of Accounting Research 38, 91-124.

Niehaus, G. and G. Roth. 1999. Insider trading, equity issues, and CEO turnover in firms subject to securities class action. Financial Management: 52-72.

Noe, C. 1999. Voluntary disclosures and insider transactions. Journal of Accounting and Economics 27: 305-326.

Penman, S. 1982. Insider trading and the dissemination of firms' forecast information. The Journal of Business 55: 479-503.

Rogers, J. and A. Van Buskirk. 2013. Bundled forecasts in empirical accounting research. Journal of Accounting and Economics 55: 43-65.

Sale, H. 2002. Judging heuristics. University of California at Davis Law Review 35: 903-963.

Seligman, J. 1994. The merits do matter: A comment on Professor Grundfest's 'Disimplying private rights of action under the federal securities laws: the commission's authority'. Harvard Law Review 108: 438-537.

Seyhun, N. and M. Bradley. 1997. Corporate bankruptcy and insider trading. Journal of Business 70: 189-216.

Skinner, D. 1994. Why firms voluntarily disclose bad news. Journal of Accounting Research 32: $38-60$.

Skinner, D. 1997. Earnings Disclosure and Stockholder Lawsuits. Journal of Accounting and Economics 23: 249-282. 


\section{Appendix A $\square$ Variable definitions for the firm-quarter trading and disclosure analyses}

For our firm-quarter trading and disclosure analyses, we assemble a sample of 107,307 firm-quarter observations for the period of 2001 through 2010 with data available from Compustat (financial statement data), CRSP (price, volume and return data), I/B/E/S (analyst forecast data from the unadjusted detail files), First Call (guidance data), and Thomson Reuters (insider trading data).

\begin{tabular}{|c|c|}
\hline BUNDLE & $\begin{array}{l}\text { An indicator variable set to } 1 \text { if the firm provided an earnings forecast during } \\
\text { the 5-day window surrounding the report date of quarterly earnings. }\end{array}$ \\
\hline N_FORECAST & $\begin{array}{l}\text { An indicator variable set to } 1 \text { if } \mathbf{B U N D L E}=\mathbf{1} \text { and the forecast estimate is less } \\
\text { than the pre-forecast prevailing median analyst estimate. }\end{array}$ \\
\hline P_FORECAST & $\begin{array}{l}\text { An indicator variable set to } 1 \text { if } \mathbf{B U N D L E}=\mathbf{1} \text { and the forecast estimate is } \\
\text { greater than the pre-forecast prevailing median analyst estimate. }\end{array}$ \\
\hline C_FORECAST & $\begin{array}{l}\text { An indicator variable set to } 1 \text { if } \mathbf{B U N D L E}=\mathbf{1} \text { and the forecast estimate is } \\
\text { equal to the pre-forecast prevailing median analyst estimate. }\end{array}$ \\
\hline GUIDE_CQTR & $\begin{array}{l}\text { An indicator variable set to } 1 \text { if the firm previously provided earnings } \\
\text { guidance for the current quarter's earnings. }\end{array}$ \\
\hline BUNDLE_PRIOR & $\begin{array}{l}\text { An indicator variable set to } 1 \text { if the firm issued an earnings forecast during the } \\
5 \text {-day window surrounding the report date of quarterly earnings last quarter. }\end{array}$ \\
\hline BUNDLE_SQLY & $\begin{array}{l}\text { An indicator variable set to } 1 \text { if the firm issued an earnings forecast during the } \\
5 \text {-day window surrounding the report date of quarterly earnings in the same } \\
\text { quarter of last year. }\end{array}$ \\
\hline RECENT_GUIDER & $\begin{array}{l}\text { An indicator variable set to } 1 \text { if the firm provided earnings guidance in any of } \\
\text { the prior } 12 \text { quarters. }\end{array}$ \\
\hline COMMITTED_GUIDER & $\begin{array}{l}\text { An indicator variable set to } 1 \text { if the firm has supplied guidance a least } 3 \text { times } \\
\text { during the past } 12 \text { quarters. }\end{array}$ \\
\hline SURPRISE & $\begin{array}{l}\text { Actual earnings minus the prevailing median analyst estimate, deflated by } \\
\text { stock price } 3 \text { trading days prior to the report date of quarterly earnings. }\end{array}$ \\
\hline P_SURPRISE & An indicator variable set to 1 if SURPRISE $>+0.0001$ \\
\hline N_SURPRISE & An indicator variable set to 1 if SURPRISE $<-0.0001$. \\
\hline LOSS & An indicator variable set to 1 if actual earnings is less than 0. \\
\hline IMPEND_BAD & $\begin{array}{l}\text { An indicator set to } 1 \text { if the firm reports disappointing earnings news in the } \\
\text { next quarter (i.e., if } \mathbf{N} \text { SURPRISE }=\mathbf{1} \text { or } \mathbf{N} \text { FORECAST }=\mathbf{1} \text { in quarter } t+1 \text { ). }\end{array}$ \\
\hline DISPERSION & $\begin{array}{l}\text { The standard deviation of prevailing analyst estimates for the current period's } \\
\text { earnings. }\end{array}$ \\
\hline PRIOR_RET & $\begin{array}{l}\text { The cumulative stock return over the } 90 \text {-day period ending } 3 \text { trading days } \\
\text { prior to the report date of quarterly earnings. }\end{array}$ \\
\hline MVE & $\begin{array}{l}\text { The market value of equity (i.e., price multiplied by shares outstanding) } \\
\text { measured } 3 \text { trading days prior to the report date of quarterly earnings. }\end{array}$ \\
\hline NUMEST & $\begin{array}{l}\text { The number of analysts with outstanding estimates } 3 \text { trading days prior to the } \\
\text { report date of quarterly earnings. }\end{array}$ \\
\hline PROPMB & $\begin{array}{l}\text { The proportion of the previous } 4 \text { quarters that the firm's reported earnings met } \\
\text { or exceeded analysts' prevailing median consensus estimates. }\end{array}$ \\
\hline $\begin{array}{l}\text { LITIGATION } \\
\text { RISK }\end{array}$ & $\begin{array}{l}\text { The ex ante probability estimate of the likelihood that the firm will be the } \\
\text { subject of } 10 \text { b-5 litigation in the next quarter, measured as the predicted } \\
\text { probability derived from a first-stage logit regression in which the dependent } \\
\text { variable is an indicator set equal to } 1 \text { if the firm faces a lawsuit in the quarter } \\
\text { and the independent variables are firm characteristics (including industry } \\
\text { membership, firm size, recent performance, share price volatility, return } \\
\text { skewness and share turnover). Specifically, we follow the litigation risk } \\
\text { model supplied in Equation (3) of Kim and Skinner (2012) to develop a } \\
\text { predicted value of litigation risk as of the prior quarter. }\end{array}$ \\
\hline VOLATILITY & $\begin{array}{l}\text { The standard deviation of daily stock returns over the } 90-\text { day period ending } 3 \\
\text { trading days prior to the report date of quarterly earnings. }\end{array}$ \\
\hline
\end{tabular}




\begin{tabular}{|c|l|}
\hline GREEN_SALES & $\begin{array}{l}\text { The total dollar value of director and officer insider sales (scaled by beginning } \\
\text { quarter market value) during the trading window starting with the release of } \\
\text { the current quarter's earnings and ending } 10 \text { trading (14 calendar) days after. }\end{array}$ \\
\hline YELLOW_SALES & $\begin{array}{l}\text { The total dollar value of director and officer insider sales (scaled by beginning } \\
\text { quarter market value) during the trading window starting } 11 \text { trading (15 } \\
\text { calendar) days after the release of the current quarter's earnings and ending at } \\
\text { the fiscal quarter end date. }\end{array}$ \\
\hline RED_SALES & $\begin{array}{l}\text { The total dollar value of director and officer insider sales (scaled by beginning } \\
\text { quarter market value) during the trading window starting with the day after } \\
\text { the fiscal quarter end date and ending the day before the release of the next } \\
\text { quarter's earnings. }\end{array}$ \\
\hline SALES_OPP & $\begin{array}{l}\text { The total dollar value of director and officer insider sales (scaled by beginning } \\
\text { quarter market value) that are classified as "opportunistic" during the trading } \\
\text { window starting with the day after the fiscal quarter end date and ending the } \\
\text { day before the release of the current quarter's earnings. We classify trades as } \\
\text { opportunistic ("OPP") based on the individual trade-level classification } \\
\text { scheme described in Cohen, Malloy and Pomorski (2012). }\end{array}$ \\
\hline SALES_ROU & $\begin{array}{l}\text { The total dollar value of director and officer insider sales (scaled by beginning } \\
\text { quarter market value) that are classified as "routine" during the trading } \\
\text { window starting with the day after the fiscal quarter end date and ending the } \\
\text { day before the release of the current quarter's earnings. We classify trades as } \\
\text { routine ("ROU") based on the individual trade-level classification scheme } \\
\text { described in Cohen, Malloy and Pomorski (2012). }\end{array}$ \\
\hline
\end{tabular}




\section{Appendix B a Variable definitions for the litigation risk analyses}

For our litigation risk analyses, we assemble a sample of 478 firms facing earnings-related litigation from 2002 through 2012 using lawsuit data obtained from Stanford Law School's Securities Class Action Clearinghouse (http://securities.stanford.edu) (SUED firms) and a sample of propensity-matched, control firms (NON-SUED firms).

\begin{tabular}{|c|c|}
\hline SUED & An indicator variable set to 1 if the firm faced earnings-related litigation. \\
\hline MVE & $\begin{array}{l}\text { The market value of equity (i.e., price multiplied by shares outstanding) at the } \\
\text { beginning of the year prior to the lawsuit filing. }\end{array}$ \\
\hline RETURN & The cumulative stock return in the year leading up to the lawsuit filing. \\
\hline VOLATILITY & $\begin{array}{l}\text { The standard deviation of daily stock returns in the year leading up to the } \\
\text { lawsuit. }\end{array}$ \\
\hline SKEWNESS & The skewness of the daily stock returns in the year prior to the lawsuit. \\
\hline TURNOVER & $\begin{array}{l}\text { The total turnover of the firm's shares in the prior year, computed as the sum of } \\
\text { the percentage turnover for each trading day in the year leading up to the lawsuit } \\
\text { filing. }\end{array}$ \\
\hline SALES_GROWTH & $\begin{array}{l}\text { The firm's change in sales (Compustat item SALE) scaled by beginning assets } \\
\text { in the year prior to the lawsuit filing. }\end{array}$ \\
\hline TECHNOLOGY & $\begin{array}{l}\text { An indicator set to } 1 \text { if the firm operates in the technology industry, as defined in } \\
\text { Field, Lowry and Shu (2005). }\end{array}$ \\
\hline RETAIL & $\begin{array}{l}\text { An indicator set to } 1 \text { if the firm operates in the retail industry, as defined in } \\
\text { Field, Lowry and Shu (2005). }\end{array}$ \\
\hline REGULATED & $\begin{array}{l}\text { An indicator set to } 1 \text { if the firm operates in a regulated industry, as defined in } \\
\text { Field, Lowry and Shu (2005). }\end{array}$ \\
\hline FPS & $\begin{array}{l}\text { An indicator variable set to } 1 \text { if the firm operates in a "high-litigation" industry, } \\
\text { as defined by Francis, Philbrick and Schipper (1994) and as employed by Kim } \\
\text { and Skinner (2012). Specifically, "high-litigation" industries include: } \\
\text { biotechnology (SIC codes 2833-2836), computers (3570-3577 and 7370-7374), } \\
\text { electronics (3600-3674), and retailing (5200-5961). }\end{array}$ \\
\hline WARN & $\begin{array}{l}\text { An indicator set to } 1 \text { if the firm issues a management forecast of negative news } \\
\text { (obtained from First Call's Company Issued Guidelines files augmented by } \\
\text { IBES guidance datafeed beginning in September of 2010) in the } 90 \text { days prior to } \\
\text { the end of the class period (the fiscal year) for sued (non-sued) firms or issues a } \\
\text { downward revision in guidance (item } 26 \text { in the Capital IQ Key Developments } \\
\text { database) during the class period (the fiscal year) for sued (non-sued) firms. }\end{array}$ \\
\hline GOOD & $\begin{array}{l}\text { An indicator set to } 1 \text { if the firm issues a management forecast of positive news } \\
\text { (obtained from First Call's Company Issued Guidelines files augmented by } \\
\text { I/B/E/S guidance datafeed beginning in September of 2010) in the year prior to } \\
\text { the end of the class period (the fiscal year) for sued (non-sued) firms or issues a } \\
\text { upward revision in guidance (item } 27 \text { in the Capital IQ Key Developments } \\
\text { database) during the class period (the fiscal year) for sued (non-sued) firms. }\end{array}$ \\
\hline $\begin{array}{l}\text { PRIOR } \\
\text { DISCLOSÜRE }\end{array}$ & $\begin{array}{l}\text { An indicator set to } 1 \text { if the firm issues guidance in the year prior to the start of } \\
\text { the class period (for sued firms) or the year prior to the start of the previous } \\
\text { fiscal year (for non-sued firms). }\end{array}$ \\
\hline SALES & The total dollar value of insider sales during the class period scaled by MVE. \\
\hline SALES_OPP & $\begin{array}{l}\text { The total dollar value of insider sales classified as "opportunistic" during the } \\
\text { class period scaled by MVE. We classify trades as opportunistic ("OPP") based } \\
\text { on the individual trade-level classification scheme described in Cohen et al. } \\
\text { (2012). }\end{array}$ \\
\hline SALES_ROU & $\begin{array}{l}\text { The total dollar value of insider sales classified as "routine" during the class } \\
\text { period scaled by MVE. We classify trades as opportunistic ("ROU") based on } \\
\text { the individual trade-level classification scheme described in Cohen et al. (2012). }\end{array}$ \\
\hline
\end{tabular}




\begin{tabular}{|c|l|}
\hline CLASS_END_RET & $\begin{array}{l}\text { For sued firms, the cumulative three-day stock return centered on the class } \\
\text { period end date. For non-sued firms, the cumulative three-day stock return } \\
\text { surrounding the firm's last earnings announcement prior to the end of the } \\
\text { "pseudo" class period. }\end{array}$ \\
\hline CLASS_PERIOD_RET & $\begin{array}{l}\text { For sued firms, the cumulative stock return over the class period. For non-sued } \\
\text { firms, the cumulative stock return for the length of time equal to the match firms' } \\
\text { class period, ending on the non-sued firm's fiscal year end date. }\end{array}$ \\
\hline SALES_AB & $\begin{array}{l}\text { Abnormal insider sales, defined as the difference in shares traded over the } \\
\text { trading window (using the same trading window as in SALES) and the same } \\
\text { period of time immediately prior to the beginning of the trading window, scaled } \\
\text { by beginning shares outstanding consistent with Johnson et al. (2007). }\end{array}$ \\
\hline
\end{tabular}


Figure 1 Insider selling and the decision to warn or to remain silent in the face of impending earnings disappointment

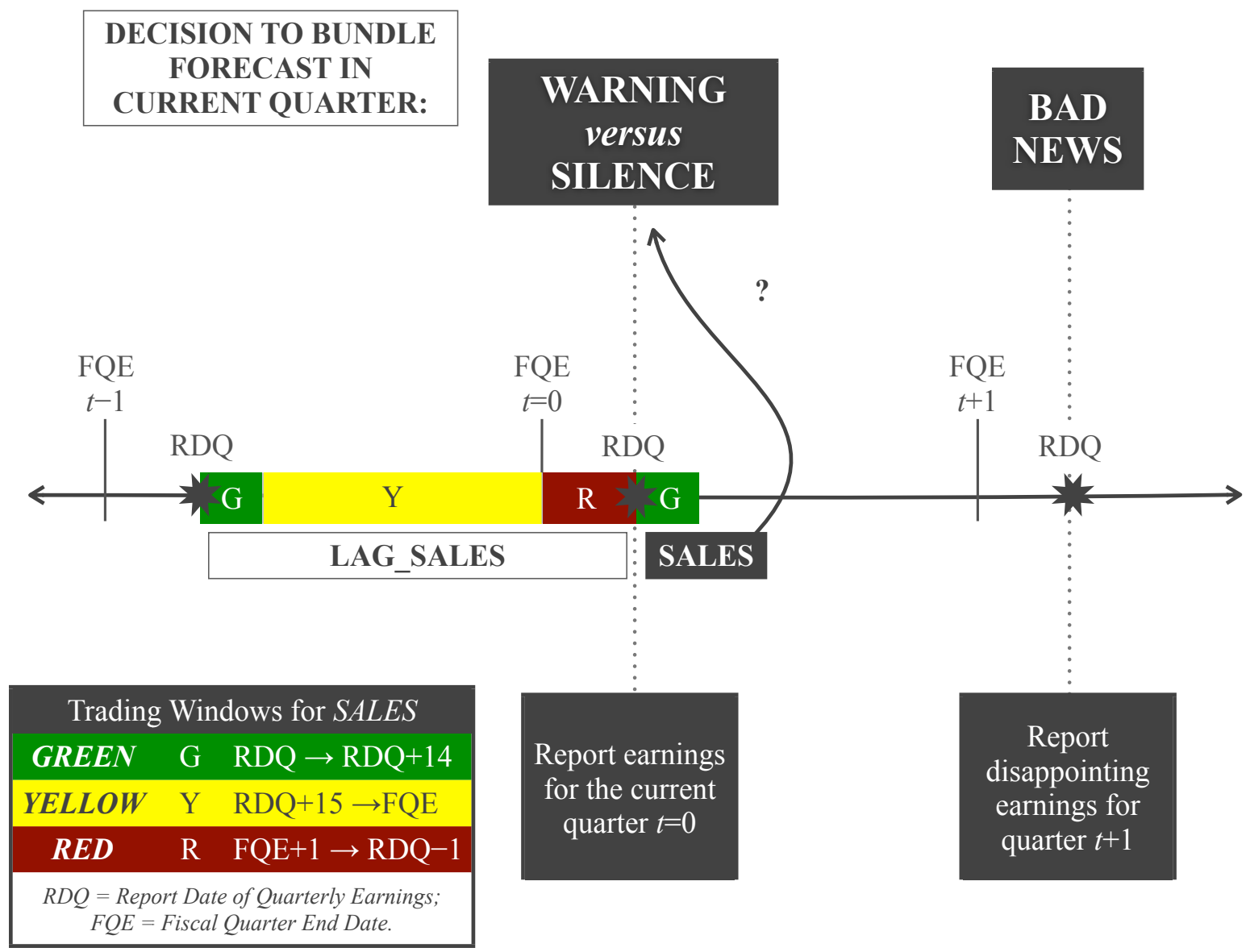


Table 1 - Descriptive statistics

Panel A examines the full sample of 107,307 firm-quarter observations from 2001 through 2010; Panel B examines the subset of 43,664 firm-quarter observations where managers face impending negative news, as measured by the presence of disappointing/negative earnings news or forecast news next quarter (IMPEND_B $\boldsymbol{A} \boldsymbol{D}=1)$. Refer to Appendix A for variable definitions and sources.

Panel A: Full sample $(n=107,307)$

\begin{tabular}{l|cccc} 
& Mean & Median & Q1 & Q3 \\
\hline BUNDLE & 0.307 & 0 & 0 & 1 \\
GUIDE_CQTR & 0.269 & 0 & 0 & 1 \\
BUNDLE_PRIOR & 0.310 & 0 & 0 & 1 \\
SURPRISE & -0.001 & -0.001 & 0.000 & 0.002 \\
P_SURPRISE & 0.581 & 0 & 1 & 1 \\
N_SURPRISE & 0.305 & 0 & 0 & 1 \\
LOSS & 0.201 & 0 & 0 & 0 \\
DISPERSION & 0.032 & 0.003 & 0.014 & 0.034 \\
PRIOR_RET & 0.033 & -0.079 & 0.040 & 0.152 \\
MVE (\$ \$illions) & 3,963 & 262 & 778 & 2,614 \\
NUMEST & 5.443 & 2 & 4 & 7 \\
PROPMB & 0.702 & 0.500 & 0.750 & 1.000 \\
P_FORECAST & 0.030 & 0.017 & 0.025 & 0.036 \\
C_FORECAST & 0.077 & 0 & 0 & 0 \\
N_FORECAST & 0.069 & 0 & 0 & 0
\end{tabular}

Panel B: Impending negative news subsample, partitioned by forecast news $(n=43,664)$

\begin{tabular}{l|cccc|cc|cc} 
& \multicolumn{2}{|c}{$\begin{array}{c}\text { Positive } \\
\text { forecast } \\
(n=3,029)\end{array}$} & \multicolumn{2}{c}{$\begin{array}{c}\text { Confirming } \\
\text { forecast } \\
(n=3,202)\end{array}$} & \multicolumn{2}{c}{$\begin{array}{c}\text { Negative } \\
\text { forecast }\end{array}$} & \multicolumn{2}{c}{$\begin{array}{c}\text { No } \\
\text { forecast } \\
(n=11,238)\end{array}$} \\
& Mean & Med. & Mean & Med. & Mean & Med. & Mean & Med. \\
\hline GUIDE_CQTR & 0.570 & 1 & 0.707 & 1 & 0.617 & 1 & 0.111 & 0 \\
BUNDLE_PRIOR & 0.848 & 1 & 0.812 & 1 & 0.851 & 1 & 0.090 & 0 \\
SURPRISE & 0.002 & 0.001 & 0.000 & 0.000 & 0.000 & 0.000 & -0.004 & 0.000 \\
P_SURPRISE & 0.726 & 1 & 0.622 & 1 & 0.610 & 1 & 0.453 & 0 \\
N_SURPRISE & 0.166 & 0 & 0.218 & 0 & 0.249 & 0 & 0.449 & 0 \\
LOSS & 0.058 & 0 & 0.097 & 0 & 0.089 & 0 & 0.300 & 0 \\
DISPERSION & 0.025 & 0.014 & 0.016 & 0.009 & 0.025 & 0.014 & 0.040 & 0.015 \\
PRIOR_RET & 0.038 & 0.048 & 0.030 & 0.039 & 0.001 & 0.020 & 0.013 & 0.023 \\
MVE & 6,331 & 1,708 & 4,391 & 967 & 5,760 & 1,435 & 2,585 & 503 \\
NUMEST & 6.6 & 5 & 5.3 & 4 & 6.9 & 6 & 4.6 & 3 \\
PROPMB & 0.820 & 1 & 0.802 & 0.75 & 0.779 & 0.75 & 0.600 & 0.5 \\
VOLATILITY & 0.024 & 0.021 & 0.026 & 0.022 & 0.026 & 0.022 & 0.033 & 0.027
\end{tabular}




\section{Table 2 a Recent and committed guiders}

Panel A examines the subset of 22,566 firm-quarters where managers face impending negative news

(IMPEND_BAD=1) and have a recent guiding history (RECENT_GUIDER=1). Panel A tabulates this subsample by the number of times the firm has bundled guidance in the past 12 quarters. Panel B displays descriptive statistics for the subset of 19,166 firm-quarter observations where managers with committed guiding histories face impending negative news (IMPEND_BAD=1 and COMMITTED_GUIDER=1). Refer to Appendix A for variable definitions and sources.

Panel A: Bundled guidance frequency for firm-quarters of recent guiders facing impending negative news $(n=22,566)$

\begin{tabular}{|c|c|c|c|c|c|c|}
\hline \multirow{2}{*}{$\begin{array}{l}\text { Recent } \\
\text { guider?• }\end{array}$} & \multirow{2}{*}{$\begin{array}{l}\text { Committed } \\
\text { guider?• }\end{array}$} & \multirow{2}{*}{$\begin{array}{c}\# \text { of bundled } \\
\text { forecasts in prior } \\
12 \text { quarters }\end{array}$} & \multicolumn{2}{|c|}{$\begin{array}{l}\text { Did the firm bundle in } \\
\text { the current quarter? }\end{array}$} & \multirow[t]{2}{*}{ Total } & \multirow{2}{*}{$\begin{array}{c}\text { \% bundled in } \\
\text { the current } \\
\text { quarter }\end{array}$} \\
\hline & & & No & Yes & & \\
\hline$\bullet$ & O & $0-2$ & 2,112 & 1,794 & 3,906 & $45.9 \%$ \\
\hline$\bullet$ & $\bullet$ & $3-6$ & 1,959 & 3,501 & 5,460 & $64.1 \%$ \\
\hline$\bullet$ & $\bullet$ & $7-9$ & 1,120 & 3,494 & 4,614 & $75.7 \%$ \\
\hline$\bullet$ & $\bullet$ & $10-12$ & 681 & 7,905 & 8,586 & $92.0 \%$ \\
\hline
\end{tabular}

- Because we define firms to have a recent guiding history if they have supplied any type of guidance (bundled or non-bundled) in the last 12 quarters, it is possible for a firm to be classified as a recent guider but not have any bundled guidance in the most recent 12 quarters (this occurs for 290 firm-quarter observations) and it is possible for a firm to be classified as a committed guider with less than 3 pieces of bundled guidance in the most recent 12 quarters (this occurs for 506 firm-quarter observations).

Panel B: Impending negative news and committed guider subsample, partitioned by forecast news $(n=19,166)$

\begin{tabular}{|c|c|c|c|c|c|c|c|c|}
\hline & \multicolumn{2}{|c|}{$\begin{array}{c}\text { Positive } \\
\text { forecast } \\
(n=2,599)\end{array}$} & \multicolumn{2}{|c|}{$\begin{array}{c}\text { Confirming } \\
\text { forecast } \\
(n=2,643)\end{array}$} & \multicolumn{2}{|c|}{$\begin{array}{c}\begin{array}{c}\text { Negative } \\
\text { forecast }\end{array} \\
(n=9,717)\end{array}$} & \multicolumn{2}{|c|}{$\begin{array}{c}\text { No } \\
\text { forecast } \\
(n=4,207)\end{array}$} \\
\hline & Mean & Med. & Mean & Med. & Mean & Med. & Mean & Med. \\
\hline GUIDE_CQTR & 0.588 & 1 & 0.748 & 1 & 0.634 & 1 & 0.359 & 0 \\
\hline BUNDLE_PRIOR & 0.905 & 1 & 0.886 & 1 & 0.901 & 1 & 0.418 & 0 \\
\hline SURPRISE & 0.001 & 0.001 & 0.001 & 0.000 & 0.000 & 0.000 & -0.005 & 0.000 \\
\hline P_SURPRISE & 0.731 & 1 & 0.633 & 1 & 0.622 & 1 & 0.481 & 0 \\
\hline N_SURPRISE & 0.164 & 0 & 0.207 & 0 & 0.241 & 0 & 0.394 & 0 \\
\hline L'̄OSS & 0.052 & 0 & 0.079 & 0 & 0.081 & 0 & 0.252 & 0 \\
\hline DISPERSION & 0.025 & 0.015 & 0.016 & 0.009 & 0.026 & 0.014 & 0.040 & 0.017 \\
\hline PRIOR_RET & 0.037 & 0.048 & 0.030 & 0.041 & 0.002 & 0.020 & 0.006 & 0.019 \\
\hline MVE & 6,822 & 1,947 & 4,819 & 1,063 & 6,076 & 1,507 & 3,472 & 727 \\
\hline NUMEST & 6.8 & 5 & 5.5 & 4 & 6.9 & 6 & 5.9 & 4 \\
\hline PROPMB & 0.827 & 1 & 0.811 & 1 & 0.783 & 0.75 & 0.676 & 0.75 \\
\hline VOLATILITY & 0.023 & 0.020 & 0.024 & 0.021 & 0.025 & 0.022 & 0.032 & 0.026 \\
\hline
\end{tabular}




\section{Table 3 a Intra-quarter insider selling}

This table documents that insiders disproportionately concentrate their trade in the days immediately following quarterly earnings releases. The sample consists of 107,307 firm-quarter observations from 2001 through 2010. Panel A provides statistics for the full sample, while Panel B provides statistics for the subset of firm-quarter observations where managers face impending negative news (IMPEND_BAD=1). We classify sales as routine ("SALES_ROU") or opportunistic ("SALES_OPP") based on the individual trade-level classification scheme described in Cohen, Malloy and Pomorski (2012). We measure insider sales over three distinct trading windows during each quarter. As shown in Figure 1, we measure GREEN_SALES as the sales most likely to be allowed under the company's insider trading policy (i.e., the sales fall in the two-week (10-day trading) period starting after the release of last quarter's earnings). We measure $\boldsymbol{R E D}$ _SALES as the sales least likely to be allowed under the company's insider trading policy (i.e., the sales that take place between current fiscal quarter end $(F Q E)$ and the current quarter's $R D Q)$. Y YELLOW_SALES capture the sales that take place between the green and the red trading windows. (Results are robust to increasing the GREEN_SALES trading window from 10 to 15 trading days.) Refer to Appendix A for variable definitions and sources.

Panel A: Full sample $(n=107,307)$

\begin{tabular}{|c|c|c|c|c|c|c|c|c|}
\hline \multicolumn{2}{|c|}{$\begin{array}{c}\text { Window classification and } \\
\text { definition }\end{array}$} & \multicolumn{2}{|c|}{$\begin{array}{c}\text { Median } \\
\text { window } \\
\text { length } \\
\text { [calendar days] }\end{array}$} & \multicolumn{2}{|c|}{$\begin{array}{c}\text { Mean insider } \\
\text { sales } \\
{[\$ \text { millions }]}\end{array}$} & \multirow{2}{*}{$\begin{array}{c}\begin{array}{c}\% \\
\text { Sales } \\
\text { ROU }\end{array} \\
13 \%\end{array}$} & \multirow{2}{*}{$\begin{array}{c}\% \\
\text { Sales } \\
\text { OPP }\end{array}$} & \multirow{2}{*}{$\begin{array}{c}\begin{array}{c}\% \\
\text { Not }\end{array} \\
\text { Class. } \\
38 \%\end{array}$} \\
\hline Green & $\mathrm{RDQ} \rightarrow \mathrm{RDQ}+14$ & 14 & $(16 \%)$ & 0.922 & $(36 \%)$ & & & \\
\hline Yellow & $\mathrm{RDQ}+15 \rightarrow \mathrm{FQE}$ & 49 & $(54 \%)$ & 1.424 & $(55 \%)$ & $10 \%$ & $52 \%$ & $38 \%$ \\
\hline Red & $\mathrm{FQE}+1 \rightarrow \mathrm{RDQ}-1$ & 27 & $(30 \%)$ & $\underline{0.227}$ & $\underline{(9 \%)}$ & $7 \%$ & $54 \%$ & $39 \%$ \\
\hline \multicolumn{2}{|c|}{ Quarterly total } & & $(100 \%)$ & $\overline{2.573}$ & $(100 \%)$ & & & \\
\hline
\end{tabular}

Panel B: Impending negative news subsample $(n=43,664)$

\begin{tabular}{|c|c|c|c|c|c|c|c|c|}
\hline \multicolumn{2}{|c|}{$\begin{array}{c}\text { Window classification and } \\
\text { definition }\end{array}$} & \multicolumn{2}{|c|}{$\begin{array}{c}\text { Median } \\
\text { window } \\
\text { length } \\
\text { [calendar days] }\end{array}$} & \multicolumn{2}{|c|}{$\begin{array}{c}\text { Mean insider } \\
\text { sales } \\
{[\$ \text { millions }]}\end{array}$} & \multirow{2}{*}{$\begin{array}{c}\% \\
\text { Sales } \\
\text { ROU }\end{array}$} & \multirow{2}{*}{$\begin{array}{c}\% \\
\text { Sales } \\
\text { OPP } \\
51 \%\end{array}$} & \multirow{2}{*}{$\begin{array}{c}\% \\
\text { Not } \\
\text { Class. } \\
35 \%\end{array}$} \\
\hline Green & $\mathrm{RDQ} \rightarrow \mathrm{RDQ}+14$ & 14 & $(16 \%)$ & 0.886 & $(36 \%)$ & & & \\
\hline Yellow & $\mathrm{RDQ}+15 \rightarrow \mathrm{FQE}$ & 49 & $(54 \%)$ & 1.342 & $(55 \%)$ & $11 \%$ & $53 \%$ & $36 \%$ \\
\hline Red & $\mathrm{FQE}+1 \rightarrow \mathrm{RDQ}-1$ & 27 & $(30 \%)$ & 0.221 & $(9 \%)$ & $7 \%$ & $55 \%$ & $38 \%$ \\
\hline \multicolumn{2}{|c|}{ Quarterly total } & & $(100 \%)$ & 2.449 & $(100 \%)$ & & & \\
\hline
\end{tabular}


Table 4 a Does insider selling affect the likelihood of issuing guidance this quarter?

The full sample consists of 107,307 firm-quarter observations from 2001 through 2010. All regression specifications include an intercept and controls for industry and time effects. $\cdots \cdot, \cdot \bullet, \cdot$ denote significance at the $1 \%$, $5 \%$, and $10 \%$ level, respectively, for two-tailed tests. Refer to Appendix A for variable definitions and sources.

Panel A: Likelihood of bundling negative forecast (i.e., warning)

Panel A tests the likelihood that an earnings announcement is bundled with a negative news forecast. We expect that the likelihood of warning increases with litigation risk and decreases with the presence of insider selling, particularly in the windows of trade (i.e., GREEN) where managers face reduced risk of penalties.

Dependent variable $=$ N_FORECAST .

Mean marginal effect (coefficient $t$-stat below)

Limit sample to:

Impending bad news

Recent guiders

Committed guiders

Current pos. surprise

CEO/CFO trades only

[2]

[3]

[4]

[5]

[6]

\begin{tabular}{|c|c|c|c|c|c|c|}
\hline litigation risk (+) & $\begin{array}{c}0.123 \bullet \bullet \\
3.92\end{array}$ & $\begin{array}{c}0.115 \bullet \bullet \\
3.61\end{array}$ & $\begin{array}{c}0.476 \bullet \bullet \\
2.92\end{array}$ & $\begin{array}{c}1.613 \bullet \bullet \bullet \\
5.07\end{array}$ & $\begin{array}{c}1.297 \bullet \bullet \bullet \\
5.03\end{array}$ & $\begin{array}{c}1.307 \bullet \bullet \bullet \\
5.21\end{array}$ \\
\hline lag_green_sales (-) & $\begin{array}{c}-0.191 \bullet \bullet \bullet \\
-2.61\end{array}$ & $\begin{array}{c}-0.314 \bullet \\
-1.94\end{array}$ & $\begin{array}{c}-0.878 \bullet \bullet \\
-2.46\end{array}$ & $\begin{array}{c}-0.886 \bullet \\
-1.79\end{array}$ & $\begin{array}{c}-1.339 \bullet \bullet \\
-2.71\end{array}$ & $\begin{array}{c}-2.758 \bullet \bullet \\
-2.98\end{array}$ \\
\hline lag_yellow_sales (?) & $\begin{array}{r}-0.086 \\
-1.49\end{array}$ & $\begin{array}{r}-0.061 \\
-1.14\end{array}$ & $\begin{array}{r}-0.353 \\
-1.27\end{array}$ & $\begin{array}{c}-0.858 \bullet \\
-1.69\end{array}$ & $\begin{array}{r}-0.569 \\
-1.52\end{array}$ & $\begin{array}{r}-0.350 \\
-0.80\end{array}$ \\
\hline lag_red_sales (?) & $\begin{array}{r}0.019 \\
0.87\end{array}$ & $\begin{array}{r}0.001 \\
0.10\end{array}$ & $\begin{array}{r}0.426 \\
0.87\end{array}$ & $\begin{array}{r}0.711 \\
1.18\end{array}$ & $\begin{array}{r}0.470 \\
0.64\end{array}$ & $\begin{array}{r}0.288 \\
0.16\end{array}$ \\
\hline green_sales (-) & $\begin{array}{c}-0.367 \bullet \bullet \\
-5.80\end{array}$ & $\begin{array}{c}-0.524 \bullet \bullet \\
-3.95\end{array}$ & $\begin{array}{c}-1.457 \bullet \bullet \\
-4.05\end{array}$ & $\begin{array}{c}-1.949 \bullet \bullet \\
-4.09\end{array}$ & $\begin{array}{c}-2.039 \bullet \bullet \\
-3.77\end{array}$ & $\begin{array}{c}-3.369 \bullet \bullet \\
-3.19\end{array}$ \\
\hline guide_cqtr & $\begin{array}{c}0.040 \bullet \bullet \\
17.12\end{array}$ & $\begin{array}{c}0.038 \bullet \bullet \\
10.13\end{array}$ & $\begin{array}{c}0.023 \bullet \bullet \\
5.14\end{array}$ & $\begin{array}{c}0.018 \bullet \bullet \\
3.89\end{array}$ & $\begin{array}{c}0.014 \bullet \bullet \\
2.44\end{array}$ & $\begin{array}{c}0.014 \bullet \bullet \\
2.44\end{array}$ \\
\hline bundle_prior & $\begin{array}{c}0.249 \bullet \bullet \bullet \\
87.32\end{array}$ & $\begin{array}{c}0.304 \bullet \bullet \bullet \\
63.62\end{array}$ & $\begin{array}{c}0.285 \bullet \bullet \\
30.06\end{array}$ & $\begin{array}{c}0.292 \bullet \bullet \bullet \\
27.97\end{array}$ & $\begin{array}{c}0.284 \bullet \bullet \bullet \\
19.51\end{array}$ & $\begin{array}{c}0.280 \bullet \bullet \\
19.50\end{array}$ \\
\hline p_surprise & $\begin{array}{c}-0.018 \bullet \bullet \bullet \\
-6.37\end{array}$ & $\begin{array}{r}0.000 \\
0.23\end{array}$ & $\begin{array}{r}-0.004 \\
-0.51\end{array}$ & $\begin{array}{r}-0.009 \\
-0.12\end{array}$ & & \\
\hline n_surprise & $\begin{array}{r}0.005 \\
0.60\end{array}$ & $\begin{array}{r}0.007 \\
0.91\end{array}$ & $\begin{array}{r}0.021 \\
1.19\end{array}$ & $\begin{array}{r}0.023 \\
1.07\end{array}$ & & \\
\hline |surprise| & $\begin{array}{c}-0.268 \bullet \bullet \\
-6.43\end{array}$ & $\begin{array}{c}-0.151 \bullet \bullet \\
-4.97\end{array}$ & $\begin{array}{c}-0.806 \bullet \bullet \\
-5.45\end{array}$ & $\begin{array}{c}-2.105 \bullet \bullet \\
-5.70\end{array}$ & $\begin{array}{c}-0.712 \bullet \bullet \\
-3.73\end{array}$ & $\begin{array}{c}-0.698 \bullet \bullet \\
-3.71\end{array}$ \\
\hline loss & $\begin{array}{c}-0.034 \bullet \bullet \bullet \\
-7.85\end{array}$ & $\begin{array}{c}-0.053 \bullet \bullet \\
-7.50\end{array}$ & $\begin{array}{c}-0.074 \bullet \bullet \bullet \\
-5.62\end{array}$ & $\begin{array}{c}-0.059 \bullet \bullet \bullet \\
-4.62\end{array}$ & $\begin{array}{c}-0.052 \bullet \bullet \\
-2.43\end{array}$ & $\begin{array}{c}-0.053 \bullet \bullet \\
-2.29\end{array}$ \\
\hline dispersion & $\begin{array}{c}-0.186 \bullet \bullet \\
-4.91\end{array}$ & $\begin{array}{c}-0.171 \bullet \bullet \\
-3.62\end{array}$ & $\begin{array}{r}-0.075 \\
-1.05\end{array}$ & $\begin{array}{r}-0.073 \\
-1.56\end{array}$ & $\begin{array}{r}-0.071 \\
-0.40\end{array}$ & $\begin{array}{r}-0.062 \\
-0.40\end{array}$ \\
\hline prior_ret & $\begin{array}{l}-0.061 \bullet \bullet \\
-12.12\end{array}$ & $\begin{array}{c}-0.049 \bullet \bullet \\
-5.72\end{array}$ & $\begin{array}{c}-0.085 \bullet \bullet \\
-5.63\end{array}$ & $\begin{array}{c}-0.106 \bullet \bullet \\
-6.13\end{array}$ & $\begin{array}{c}-0.124 \bullet \bullet \bullet \\
-5.33\end{array}$ & $\begin{array}{c}-0.126 \bullet \bullet \\
-5.70\end{array}$ \\
\hline $\log (\mathrm{mve})$ & $\begin{array}{c}0.004 \bullet \bullet \\
3.57\end{array}$ & $\begin{array}{c}0.010 \bullet \bullet \\
5.97\end{array}$ & $\begin{array}{c}0.013 \bullet \bullet \\
4.85\end{array}$ & $\begin{array}{c}0.009 \bullet \bullet \\
3.23\end{array}$ & $\begin{array}{c}0.010 \bullet \bullet \\
2.18\end{array}$ & $\begin{array}{c}0.010 \bullet \bullet \\
2.40\end{array}$ \\
\hline $\log ($ numest $)$ & $\begin{array}{c}0.024 \bullet \bullet \bullet \\
14.72\end{array}$ & $\begin{array}{c}0.033 \bullet \bullet \bullet \\
11.87\end{array}$ & $\begin{array}{c}0.046 \bullet \bullet \\
8.08\end{array}$ & $\begin{array}{c}0.042 \bullet \bullet \\
7.08\end{array}$ & $\begin{array}{c}0.033 \bullet \bullet \bullet \\
3.76\end{array}$ & $\begin{array}{c}0.033 \bullet \bullet \\
3.79\end{array}$ \\
\hline probmb & $\begin{array}{c}-0.018 \bullet \bullet \\
-2.19\end{array}$ & $\begin{array}{r}0.006 \\
1.40\end{array}$ & $\begin{array}{c}-0.044 \bullet \bullet \\
-2.01\end{array}$ & $\begin{array}{c}-0.047 \bullet \bullet \\
-2.40\end{array}$ & $\begin{array}{c}-0.067 \bullet \bullet \bullet \\
-2.57\end{array}$ & $\begin{array}{c}-0.064 \bullet \bullet \\
-2.67\end{array}$ \\
\hline volatility & $\begin{array}{c}-0.168 \bullet \bullet \\
-2.40\end{array}$ & $\begin{array}{r}-0.081 \\
-1.41 \\
\end{array}$ & $\begin{array}{r}-0.202 \\
-1.13 \\
\end{array}$ & $\begin{array}{r}-0.122 \\
-1.18 \\
\end{array}$ & $\begin{array}{r}0.328 \\
0.35\end{array}$ & $\begin{array}{r}0.317 \\
0.40\end{array}$ \\
\hline $\begin{array}{l}n \\
\text { Pseudo } \mathbf{R}^{2} \\
\text { ROC area }\end{array}$ & $\begin{array}{r}107,307 \\
23.2 \% \\
0.854\end{array}$ & $\begin{array}{r}43,664 \\
29.9 \% \\
0.854\end{array}$ & $\begin{array}{r}22,566 \\
12.0 \% \\
0.694\end{array}$ & $\begin{array}{r}19,166 \\
10.5 \% \\
0.679\end{array}$ & $\begin{array}{r}11,639 \\
8.6 \% \\
0.665\end{array}$ & $\begin{array}{r}11,639 \\
8.5 \% \\
0.664\end{array}$ \\
\hline
\end{tabular}




\section{Table 4 a Does insider selling affect the likelihood of issuing guidance this quarter? (continued)}

\section{Panel B: Likelihood of bundling positive forecast}

Panel B tests the likelihood that an earnings announcement is bundled with a positive news forecast. We expect that the likelihood of a positive news disclosure decreases with litigation risk and increases with the presence of insider selling, particularly in the windows of trade (i.e., GREEN) where managers face reduced risk of penalties.

Dependent variable $=P$ PORECAST .

Mean marginal effect (coefficient $t$-stat below)

Limit sample to:

[2

[3]

[4]

[5]

Impending bad news

Recent guiders

Committed guiders

Current pos. surprise

CEO/CFO trades only

0
0
0
0
0

$\begin{array}{lcccccc}\text { litigation risk (-) } & -0.271 \bullet \bullet & -0.363 \bullet \bullet & -0.612 \bullet \bullet & -0.829 \bullet \bullet & -0.961 \bullet \bullet \bullet & -1.149 \bullet \bullet \\ & -7.81 & -6.12 & -6.46 & -6.50 & -5.72 & -5.93 \\ \text { lag_green_sales }(+) & 0.192 \bullet \bullet & 0.325 \bullet \bullet & 0.721 \bullet \bullet & 0.827 \bullet \bullet & 1.185 \bullet \bullet & 1.454 \bullet \bullet \\ & 5.45 & 5.20 & 5.10 & 4.93 & 4.91 & 3.53 \\ \text { lag_yellow_sales (?) } & 0.045 & -0.067 & -0.094 & 0.159 & 0.203 & -0.222 \\ & 0.05 & -0.22 & -0.12 & 0.19 & 0.22 & -0.95 \\ \text { lag_red_sales (?) } & 0.027 & -0.009 & -0.079 & -0.214 & -0.247 & -0.406 \\ & 0.39 & -0.60 & -0.44 & -0.94 & -0.76 & -0.64 \\ \text { green_sales }(+) & 0.260 \bullet \bullet & 0.248 \bullet \bullet & 0.538 \bullet \bullet & 0.731 \bullet \bullet & 0.972 \bullet \bullet & 1.651 \bullet \bullet \\ & 6.78 & 3.73 & 3.28 & 3.73 & 3.34 & 3.38\end{array}$

Other controls included: Industry effects, time effects, guide_cqtr, bundle_prior, $p \_s u r p r i s e, n \_s u r p r i s e$, |surprise|, loss, dispersion, prior_ret, $\log (m v e), \log ($ numest), probmb, and volatility.

$n$
Pseudo $\mathbf{R}^{2}$
ROC area

107,307
$11.6 \%$

0.836

43,664
$8.1 \%$
0.805

0.805

22,566
$4.5 \%$
0.679

0.679

$\begin{array}{rrr}19,166 & 11,639 & 11,639 \\ 4.4 \% & 4.1 \% & 3.9 \% \\ 0.675 & 0.656 & 0.653\end{array}$




\section{Table 4 - Does insider selling affect the likelihood of issuing guidance this quarter? (continued)}

\section{Panel C: Likelihood of bundling when there is increased expectation of warning}

Panel $\mathrm{C}$ tests the likelihood that an earnings announcement is bundled with a news forecast for the subset of 11,716 firm-quarter observations where managers with committed guiding histories face impending negative news and increased expectation of warning (i.e., COMMITTED_GUIDER=1, IMPEND_BAD=1, BUNDLE_PRIOR=1, and $\left.\boldsymbol{B} \boldsymbol{U} N \boldsymbol{L} \boldsymbol{E} \_\boldsymbol{S} \boldsymbol{Q} \boldsymbol{L} \boldsymbol{Y}=1\right)$. Specifications [1] and [2] predict the issuance of a negative forecast; Specifications [3] and [4] predict the issuance of a positive forecast. In specfications [1] and [2], we expect that the likelihood of warning increases with litigation risk and decreases with the presence of insider selling, particularly in the windows of trade (i.e., GREEN) where managers face reduced risk of penalties. In specifications [3] and [4], we expect that the likelihood of a positive news disclosure decreases with litigation risk and increases with the presence of insider selling, particularly in the windows of trade (i.e., GREEN) where managers face reduced risk of penalties.

Dependent variable $=$ FORECAST . Mean marginal effect (coefficient $t$-stat below)

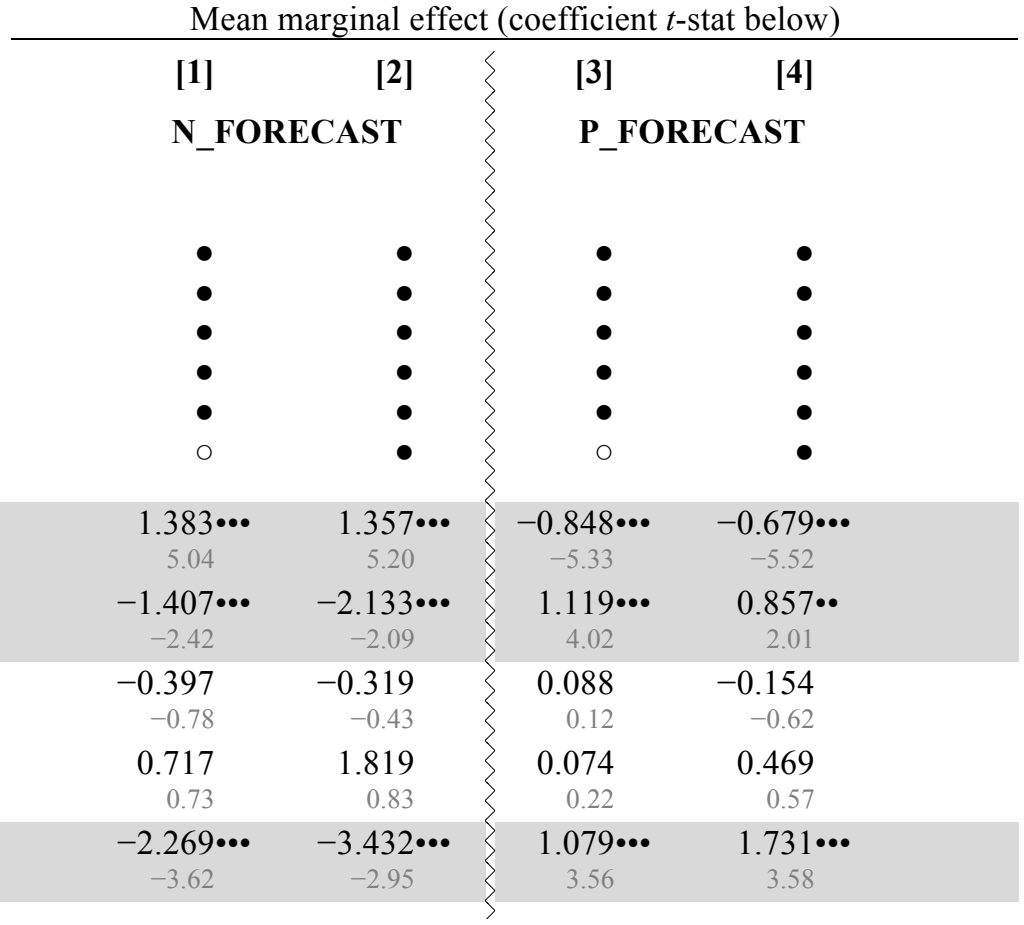

Other controls included: Industry effects, time effects, guide_cqtr, bundle_prior, $p \_s u r p r i s e, n \_s u r p r i s e$, |surprise|, loss, dispersion, prior_ret, $\log (m v e), \log$ (numest), probmb, and volatility.

$n$

Pseudo $\mathbf{R}^{2}$

ROC area

$\begin{array}{rrrr}11,716 & 11,716 & 11,716 & 11,716 \\ 3.9 \% & 3.8 \% & 3.9 \% & 3.7 \% \\ 0.614 & 0.613 & 0.652 & 0.649\end{array}$

Limit sample to:

Impending bad news

Recent guiders

Committed guiders

Bundled in same quarter last year

litigation risk $(+/+/-/-)$

lag_green_sales $(-/-/+/+)$

lag_yellow_sales (?)

lag_red_sales (?)

green_sales $(-/-/+/+)$

样

$\mathrm{CEO} / \mathrm{CFO}$ trades only 
Table 5 a Does opportunistic selling affect the likelihood of issuing guidance this quarter? The sample consists of 107,307 firm-quarter observations from 2001 through 2010. We classify trades as routine ("SALES_ROU") or opportunistic ("SALES_OPP") based on the individual trade-level classification scheme described in Cohen, Malloy and Pomorski (2012). All regression specifications include an intercept, controls for industry and time effects, and include the control variables shown in Table $3 . \cdots, \cdot \bullet, \cdot$ denote significance at the $1 \%$, $5 \%$, and $10 \%$ level, respectively, for two-tailed tests. Refer to Appendix A for variable definitions and sources.

\section{Panel A: Likelihood of bundling negative forecast (i.e., warning)}

Panel A tests the likelihood that an earnings announcement is bundled with a negative news forecast. We expect that the likelihood of warning increases with litigation risk and decreases with the presence of opportunistic insider selling, particularly in the windows of trade (i.e., GREEN) where managers face reduced risk of penalties.

Dependent variable $=$ N_FORECAST .

Mean marginal effect (coefficient $t$-stat below)

Limit sample to:

Impending bad news

Recent guiders

Committed guiders

Current pos. surprise

CEO/CFO trades only

[2]

[3]

[4]

[5]

[6]

\begin{tabular}{|c|c|c|c|c|c|c|}
\hline litigation risk (+) & $\begin{array}{c}0.100 \bullet \bullet \\
4.01\end{array}$ & $\begin{array}{c}0.108 \bullet \bullet \\
3.69\end{array}$ & $\begin{array}{c}0.385 \bullet \bullet \\
3.00\end{array}$ & $\begin{array}{c}1.416 \bullet \bullet \\
5.17\end{array}$ & $\begin{array}{c}1.292 \bullet \bullet \\
5.16\end{array}$ & $\begin{array}{c}1.193 \bullet \bullet \\
5.28\end{array}$ \\
\hline \multicolumn{7}{|l|}{ Opportunistic sales: } \\
\hline$\overline{\text { lag_green_sales (-) }}$ & $\begin{array}{r}-0.120 \\
-1.07\end{array}$ & $\begin{array}{r}-0.185 \\
-0.76\end{array}$ & $\begin{array}{r}-0.664 \\
-1.23\end{array}$ & $\begin{array}{r}-0.605 \\
-0.95\end{array}$ & $\begin{array}{c}-1.909 \bullet \bullet \\
-2.33\end{array}$ & $\begin{array}{c}-3.305 \bullet \bullet \\
-2.36\end{array}$ \\
\hline lag_yellow_sales (?) & $\begin{array}{r}-0.047 \\
-1.04\end{array}$ & $\begin{array}{r}-0.042 \\
-0.26\end{array}$ & $\begin{array}{r}-0.163 \\
-0.34\end{array}$ & $\begin{array}{r}-0.385 \\
-0.60\end{array}$ & $\begin{array}{r}-0.576 \\
-1.17\end{array}$ & $\begin{array}{r}-0.440 \\
-0.66\end{array}$ \\
\hline lag_red_sales (?) & $\begin{array}{r}0.121 \\
1.50\end{array}$ & $\begin{array}{r}0.153 \\
0.78\end{array}$ & $\begin{array}{r}0.873 \\
1.19\end{array}$ & $\begin{array}{r}1.201 \\
1.36\end{array}$ & $\begin{array}{r}0.608 \\
0.58\end{array}$ & $\begin{array}{r}-1.528 \\
-0.61\end{array}$ \\
\hline green_sales (-) & $\begin{array}{c}-0.396 \bullet \bullet \\
-4.64\end{array}$ & $\begin{array}{c}-0.685 \bullet \bullet \\
-3.52\end{array}$ & $\begin{array}{c}-1.922 \bullet \bullet \bullet \\
-3.81\end{array}$ & $\begin{array}{c}-2.092 \bullet \bullet \\
-3.64\end{array}$ & $\begin{array}{c}-3.107 \bullet \bullet \\
-3.34\end{array}$ & $\begin{array}{c}-3.020 \bullet \bullet \\
-2.06\end{array}$ \\
\hline \multicolumn{7}{|l|}{ Routine sales: } \\
\hline lag_green_sales (?) & $\begin{array}{r}-0.192 \\
-0.62\end{array}$ & $\begin{array}{c}-0.961 \bullet \\
-1.76\end{array}$ & $\begin{array}{r}-1.921 \\
-1.37\end{array}$ & $\begin{array}{r}-2.349 \\
-1.08\end{array}$ & $\begin{array}{r}-1.561 \\
-0.64\end{array}$ & $\begin{array}{r}-0.452 \\
-0.06\end{array}$ \\
\hline lag_yellow_sales (?) & $\begin{array}{r}0.017 \\
0.42\end{array}$ & $\begin{array}{r}-0.134 \\
-0.56\end{array}$ & $\begin{array}{r}-0.379 \\
-0.54\end{array}$ & $\begin{array}{r}-1.033 \\
-1.09\end{array}$ & $\begin{array}{r}1.050 \\
0.79\end{array}$ & $\begin{array}{r}-4.986 \\
-1.05\end{array}$ \\
\hline lag_red_sales (?) & $\begin{array}{r}0.034 \\
0.19\end{array}$ & $\begin{array}{r}0.672 \\
0.64\end{array}$ & $\begin{array}{r}2.200 \\
0.77\end{array}$ & $\begin{array}{r}2.657 \\
0.85\end{array}$ & $\begin{array}{r}1.716 \\
0.56\end{array}$ & $\begin{array}{r}-1.238 \\
-0.10\end{array}$ \\
\hline green_sales (?) & $\begin{array}{r}-0.480 \\
-1.37\end{array}$ & $\begin{array}{r}0.032 \\
0.03\end{array}$ & $\begin{array}{r}-0.257 \\
-0.13\end{array}$ & $\begin{array}{r}0.361 \\
0.20\end{array}$ & $\begin{array}{r}-2.162 \\
-0.98\end{array}$ & $\begin{array}{r}-5.450 \\
-1.01\end{array}$ \\
\hline
\end{tabular}

Other controls included: Industry effects, time effects, guide_cqtr, bundle_prior, $p \_s u r p r i s e, n \_s u r p r i s e$, |surprise|, loss, dispersion, prior_ret, $\log (m v e), \log ($ numest), probmb, and volatility.

\begin{tabular}{|c|c|c|c|c|c|c|}
\hline$n$ & 107,307 & 43,664 & 22,566 & 19,166 & 11,639 & 11,639 \\
\hline Pseudo $\mathbf{R}^{2}$ & $23.1 \%$ & $29.9 \%$ & $12.0 \%$ & $10.4 \%$ & $8.5 \%$ & $8.5 \%$ \\
\hline ROC area & 0.854 & 0.854 & 0.694 & 0.679 & 0.664 & 0.663 \\
\hline
\end{tabular}




\section{Table 5 - Does opportunistic selling affect the likelihood of issuing guidance this quarter? (continued)}

\section{Panel B: Likelihood of bundling positive forecast}

Panel B tests the likelihood that an earnings announcement is bundled with a positive news forecast. We expect that the likelihood of a positive news disclosure decreases with litigation risk and increases with the presence of

opportunistic insider selling, particularly in the windows of trade (i.e., GREEN) where managers face reduced risk of penalties.

Dependent variable $=$ P_FORECAST .

Mean marginal effect (coefficient $t$-stat below)

\begin{tabular}{|c|c|c|c|c|c|c|}
\hline & [1] & [2] & [3] & [4] & [5] & [6] \\
\hline \multicolumn{7}{|l|}{ Limit sample to: } \\
\hline Impending bad news & ○ & $\bullet$ & $\bullet$ & $\bullet$ & $\bullet$ & $\bullet$ \\
\hline Recent guiders & ० & ○ & $\bullet$ & $\bullet$ & $\bullet$ & $\bullet$ \\
\hline Committed guiders & ○ & o & ○ & $\bullet$ & $\bullet$ & $\bullet$ \\
\hline Current pos. surprise & ○ & O & ० & ○ & $\bullet$ & $\bullet$ \\
\hline $\mathrm{CEO} / \mathrm{CFO}$ trades only & ० & $\circ$ & ० & ○ & ○ & $\bullet$ \\
\hline litigation risk (-) & $\begin{array}{c}-0.307 \bullet \bullet \bullet \\
-7.98\end{array}$ & $\begin{array}{c}-0.353 \bullet \bullet \\
-6.21\end{array}$ & $\begin{array}{c}-0.493 \bullet \bullet \\
-6.56\end{array}$ & $\begin{array}{c}-0.807 \bullet \bullet \\
-6.60\end{array}$ & $\begin{array}{c}-1.109 \bullet \bullet \bullet \\
-5.81\end{array}$ & $\begin{array}{c}-1.145 \bullet \bullet \\
-6.00\end{array}$ \\
\hline \multicolumn{7}{|l|}{ Opportunistic sales: } \\
\hline lag_green_sales (+) & $\begin{array}{c}0.188 \bullet \bullet \\
4.20\end{array}$ & $\begin{array}{c}0.272 \bullet \bullet \\
3.66\end{array}$ & $\begin{array}{c}0.645 \bullet \bullet \\
3.20\end{array}$ & $\begin{array}{c}0.673 \bullet \bullet \\
2.91\end{array}$ & $\begin{array}{c}1.225 \bullet \bullet \\
3.09\end{array}$ & $\begin{array}{c}1.404 \bullet \bullet \\
2.19\end{array}$ \\
\hline lag_yellow_sales (?) & $\begin{array}{r}0.023 \\
0.34\end{array}$ & $\begin{array}{r}0.052 \\
0.82\end{array}$ & $\begin{array}{r}0.119 \\
0.81\end{array}$ & $\begin{array}{r}0.220 \\
1.17\end{array}$ & $\begin{array}{r}0.311 \\
1.07\end{array}$ & $\begin{array}{r}-0.399 \\
-1.17\end{array}$ \\
\hline lag_red_sales (?) & $\begin{array}{r}-0.033 \\
-0.73\end{array}$ & $\begin{array}{r}-0.061 \\
-1.11\end{array}$ & $\begin{array}{r}-0.293 \\
-1.14\end{array}$ & $\begin{array}{r}-0.414 \\
-1.20\end{array}$ & $\begin{array}{r}-0.532 \\
-1.04\end{array}$ & $\begin{array}{r}-1.100 \\
-1.00\end{array}$ \\
\hline green_sales (+) & $\begin{array}{c}0.258 \bullet \bullet \\
5.29\end{array}$ & $\begin{array}{c}0.260 \bullet \bullet \\
3.58\end{array}$ & $\begin{array}{c}0.616 \bullet \bullet \\
3.13\end{array}$ & $\begin{array}{c}0.764 \bullet \bullet \\
3.10\end{array}$ & $\begin{array}{c}1.302 \bullet \bullet \bullet \\
2.97\end{array}$ & $\begin{array}{c}1.572 \bullet \bullet \\
2.36\end{array}$ \\
\hline \multicolumn{7}{|l|}{ Routine sales: } \\
\hline$\overline{\text { lag_green_sales (?) }}$ & $\begin{array}{r}0.141 \\
0.60\end{array}$ & $\begin{array}{r}-0.019 \\
-0.41\end{array}$ & $\begin{array}{r}-0.060 \\
-0.26\end{array}$ & $\begin{array}{r}-0.055 \\
-0.13\end{array}$ & $\begin{array}{r}-0.238 \\
-0.20\end{array}$ & $\begin{array}{r}-2.190 \\
-0.89\end{array}$ \\
\hline lag_yellow_sales (?) & $\begin{array}{c}-0.016 \bullet \\
-1.77\end{array}$ & $\begin{array}{r}-0.052 \\
-0.46\end{array}$ & $\begin{array}{r}-0.084 \\
-0.34\end{array}$ & $\begin{array}{r}-0.223 \\
-0.52\end{array}$ & $\begin{array}{r}-0.306 \\
-0.48\end{array}$ & $\begin{array}{r}2.499 \\
1.15\end{array}$ \\
\hline lag_red_sales (?) & $\begin{array}{c}0.485 \bullet \\
1.74\end{array}$ & $\begin{array}{r}0.037 \\
0.22\end{array}$ & $\begin{array}{r}0.193 \\
0.31\end{array}$ & $\begin{array}{r}0.283 \\
0.41\end{array}$ & $\begin{array}{r}0.640 \\
0.67\end{array}$ & $\begin{array}{r}9.530 \\
1.35\end{array}$ \\
\hline green_sales (?) & $\begin{array}{r}0.175 \\
0.53\end{array}$ & $\begin{array}{r}0.054 \\
0.15\end{array}$ & $\begin{array}{r}0.063 \\
0.15\end{array}$ & $\begin{array}{r}0.147 \\
0.29\end{array}$ & $\begin{array}{r}0.627 \\
0.73\end{array}$ & $\begin{array}{r}2.170 \\
1.07\end{array}$ \\
\hline
\end{tabular}

Other controls included: Industry effects, time effects, guide_cqtr, bundle_prior, $p \_s u r p r i s e, n \_s u r p r i s e$, |surprise|, loss, dispersion, prior_ret, $\log (m v e), \log ($ numest), probmb, and volatility.

\begin{tabular}{|c|c|c|c|c|c|c|}
\hline$n$ & 107,307 & 43,664 & 22,566 & 19,166 & 11,639 & 11,639 \\
\hline Pseudo $\mathbf{R}^{2}$ & $11.6 \%$ & $8.1 \%$ & $4.4 \%$ & $4.3 \%$ & $3.9 \%$ & $3.9 \%$ \\
\hline ROC area & 0.836 & 0.804 & 0.678 & 0.673 & 0.653 & 0.652 \\
\hline
\end{tabular}




\section{Table 6 a Descriptive statistics for lawsuit and propensity-matched control sample}

This table provides descriptive statistics for a sample of 478 firms facing earnings-related litigation from 2002 through 2012 using lawsuit data obtained from Stanford Law School's Securities Class Action Clearinghouse (http://securities.stanford.edu) (SUED firms) and a sample of propensity-matched, control firms (NON-SUED firms). Specifically, using the litigation risk model supplied in Equation (3) of Kim and Skinner (2012), we assemble a propensity-matched control sample of firms facing similar litigation risk. As detailed in Kim and Skinner (2012), the litigation risk model includes the following variables: FPS, Log Assets, Sales Growth, Return, Skewness, Volatility, and Turnover. We supply statistics for the SUED and NON-SUED firms. $\cdots, \cdot, \cdot, \cdot$ denote instances where the two samples differ significantly at the $1 \%, 5 \%$, and $10 \%$ level, respectively, for two-tailed tests. Refer to Appendix B for variable definitions and sources.

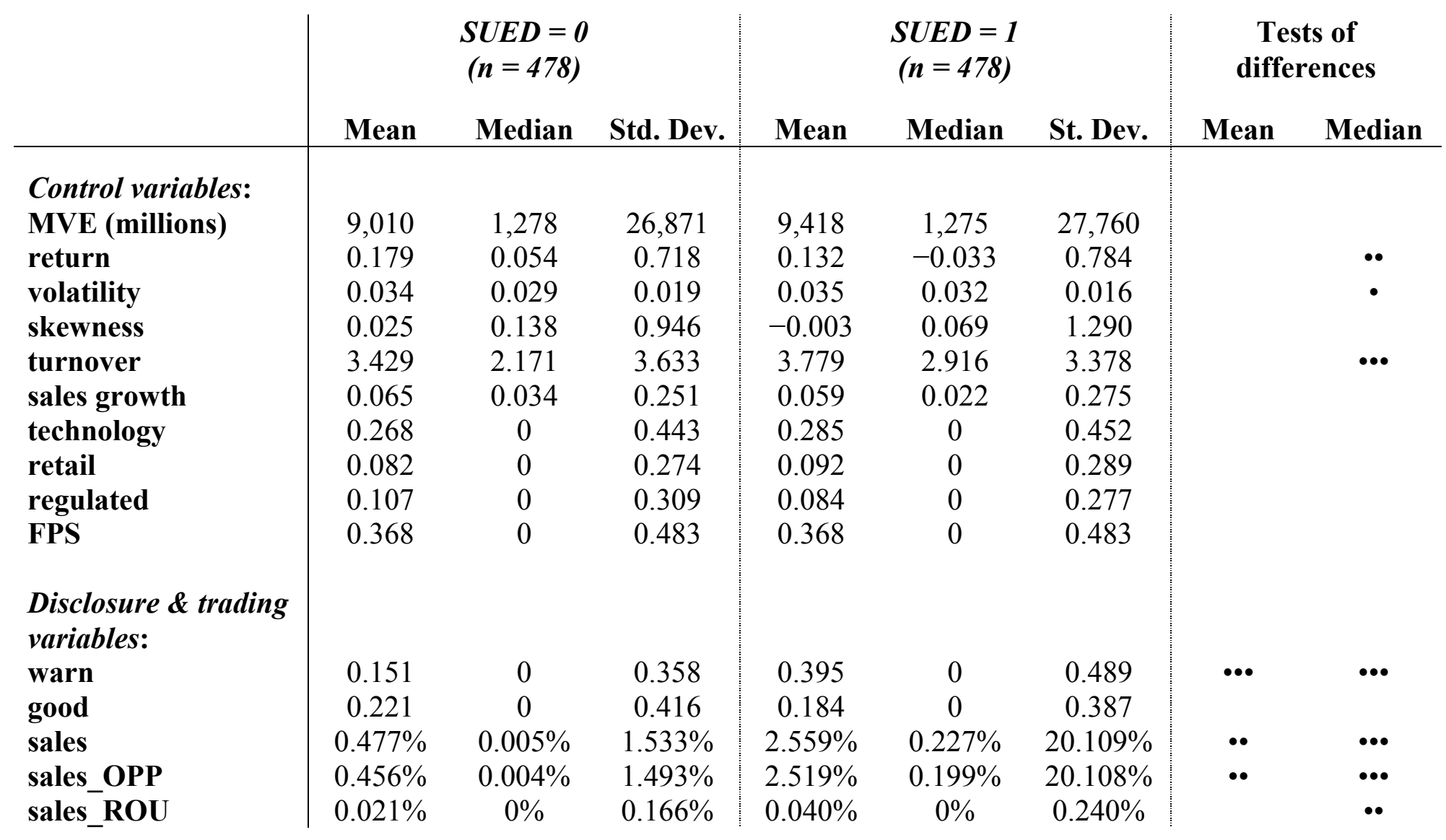


Table 7 a Does disclosure deter litigation? (Replication of Field, Lowry and Shu 2005)

This table replicates the main results of Field, Lowry and Shu (2005). Specification [1] confirms the presence of a preemption effect in our sample: firms with higher litigation risk are more likely to warn of bad news early. Specification [2] confirms that, absent efforts to address the endogeneity between warning and litigation risk, warning appears to increase firms' litigation risk. Specifications [3], [4], [5], and [6] use a simultaneous-equations framework to develop a predicted value of WARN in order to confirm the presence of a deterrence effect in our sample: the WARN instrument is associated with reduced likelihood of litigation after controlling for the positive relation between litigation risk and the likelihood of early warning. Specifications [5] and [6] limit analysis to nondismissed lawsuits (and their associated control firms). Results are robust to the inclusion of FPS (an indicator variable coded based on the high-litigation industries identified by Francis et al. (1994) and used by Kim and Skinner (2012)) instead of technology, regulated and retail, as well as the inclusion of an indicator for the fourth quarter and sales growth. $\cdots, \cdot \bullet, \bullet$ denote significance at the $1 \%, 5 \%$, and $10 \%$ level, respectively, for two-tailed tests. Intercept included but not reported. Refer to Appendix B for variable definitions and sources.

Dependent variable $=$ WARN or SUED.

Mean marginal effect (coefficient $t$-stat below)

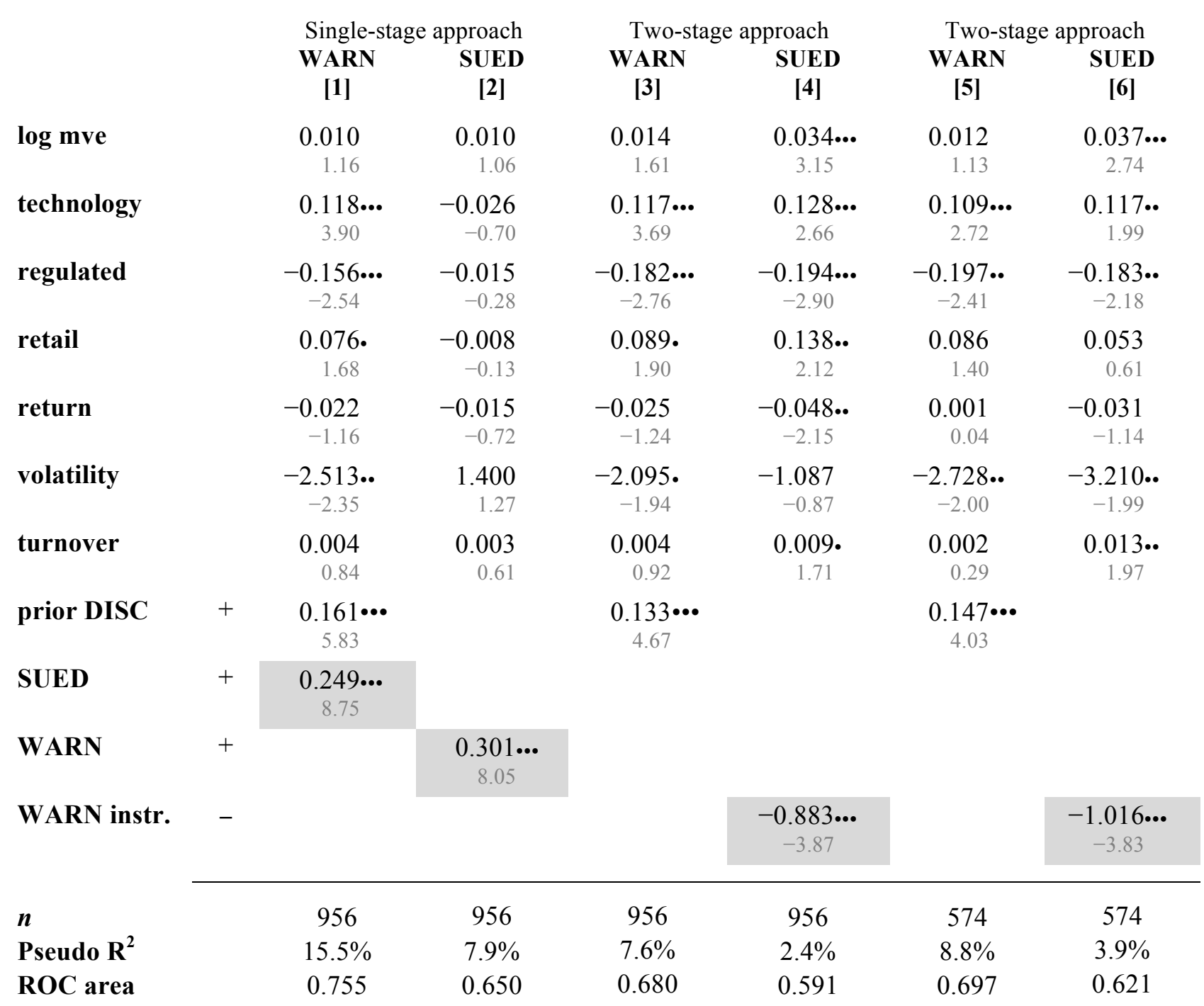




\section{Table 8 — Does disclosure deter litigation when managers' trading behavior is considered?}

\section{Panel A: Silence combined with trading and litigation risk}

In Panel A, we present the results of the second-stage litigation risk regression (dependent variable: $\mathrm{SUED}=1$ ), following Field, Lowry and Shu (2005) (as shown in specifications [4] and [6] of Table 7). We obtain a predicted value for silence (i.e., WARN $=0$ ) by reversing the predicted value of WARN in the regressions. The inclusion of silence tests for evidence of a deterrence effect (i.e., failure to warn associated with increased litigation risk). The interaction of sales with silence tests for evidence that the combined behavior of selling and silence is associated with increased litigation risk. Specification [1] presents the results without trading variables. Specification [2] measures sales using the length of the class period as the trading window. Specification [3] uses CEO and CFO trades only. Specification [4] classifies trades as routine ("SALES_ROU") or opportunistic ("SALES_OPP") based on the trade-level classification scheme in Cohen, Malloy and Pomorski (2012). Specification [5] measures trading as the difference in shares traded during the class period and the equivalent length of time immediately prior to the beginning of the class period, scaled by shares outstanding, consistent with Johnson et al. (2007). The inclusion of good in Specification [6] tests for increased litigation risk associated with supplying a good news forecast at any point during the class period prior to either the delivery of a bad news warning or the end of the class period; the interaction of good with silence tests for increased litigation risk associated with the delivery of a good news forecast in combination with the failure to warn during the class period. The additional control variables from Table 7 are included but not tabulated. $\bullet \bullet, \bullet, \bullet$ denote significance at the $1 \%, 5 \%$, and $10 \%$ level, respectively, for twotailed tests. Refer to Appendix B for variable definitions and sources.

Dependent variable $=$ SUED.

Mean marginal effect (coefficient $t$-stat below)

\begin{tabular}{|c|c|c|c|c|c|c|}
\hline & \multicolumn{6}{|c|}{ 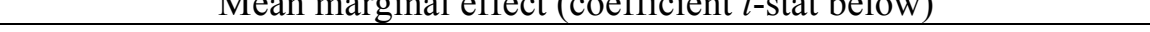 } \\
\hline & {$[1]$} & [2] & {$[3]$} & {$[4]$} & {$[5]$} & {$[6]$} \\
\hline silence $(+)$ & $\begin{array}{c}0.883 \bullet \bullet \\
3.87\end{array}$ & $\begin{array}{c}0.479 \bullet \bullet \\
2.61\end{array}$ & $\begin{array}{c}0.487 \bullet \bullet \bullet \\
2.60\end{array}$ & $\begin{array}{c}0.500 \bullet \bullet \\
2.74\end{array}$ & $\begin{array}{c}0.475 \bullet \bullet \\
2.49\end{array}$ & $\begin{array}{r}0.326 \\
1.60\end{array}$ \\
\hline sales (+) & & $\begin{array}{c}11.010 \bullet \bullet \\
6.26\end{array}$ & $\begin{array}{c}21.800 \bullet \bullet \\
5.29\end{array}$ & & & $\begin{array}{c}10.926 \bullet \bullet \bullet \\
6.28\end{array}$ \\
\hline sales $\times$ silence $(+)$ & & $\begin{array}{c}10.829 \bullet \bullet \\
5.89\end{array}$ & $\begin{array}{c}21.392 \bullet \bullet \\
5.07\end{array}$ & & & $\begin{array}{c}10.688 \bullet \bullet \\
5.89\end{array}$ \\
\hline sales_opp (+) & & & & $\begin{array}{c}11.481 \bullet \bullet \\
6.27\end{array}$ & & \\
\hline sales_opp $\times$ silence $(+)$ & & & & $\begin{array}{c}11.259 \bullet \bullet \\
5.91\end{array}$ & & \\
\hline sales_rou (+) & & & & $\begin{array}{r}-12.93 \\
-1.55\end{array}$ & & \\
\hline sales_rou $\times$ silence $(+)$ & & & & $\begin{array}{r}-65.17 \\
-1.07\end{array}$ & & \\
\hline sales_ab (+) & & & & & $\begin{array}{c}4.205 \bullet \bullet \\
2.83\end{array}$ & \\
\hline sales_ab $\times$ silence $(+)$ & & & & & $\begin{array}{c}8.407 \bullet \bullet \bullet \\
2.93\end{array}$ & \\
\hline $\operatorname{good}(+)$ & & & & & & $\begin{array}{r}0.155 \\
1.52\end{array}$ \\
\hline good $\times$ silence $(+)$ & & & & & & $\begin{array}{c}0.545 \bullet \bullet \\
1.98\end{array}$ \\
\hline Intercept & Yes & Yes & Yes & Yes & Yes & Yes \\
\hline Table 7 controls & Yes & Yes & Yes & Yes & Yes & Yes \\
\hline Pseudo $\mathbf{R}^{2}$ & $20.0 \%$ & $25.0 \%$ & $23.7 \%$ & $25.2 \%$ & $21.3 \%$ & $25.4 \%$ \\
\hline ROC area & 0.790 & 0.821 & 0.812 & 0.822 & 0.798 & 0.824 \\
\hline$n$ & 956 & 956 & 956 & 956 & 956 & 956 \\
\hline
\end{tabular}


Table 8 a Does disclosure deter litigation when managers' trading behavior is considered? (continued)

Panel B: Warning combined with trading and litigation risk

In Panel B we present the second-stage results after reversing the first-stage prediction (i.e., predicting WARN=1). The interaction of sales with warn tests whether insider selling moderates the deterrence effect of disclosure. •.•, $, \bullet, \bullet$ denote significance at the $1 \%, 5 \%$, and $10 \%$ level, respectively, for two-tailed tests. Refer to Appendix B for variable definitions and sources.

\begin{tabular}{|l|c|c|c|c|c|}
\hline & & \multicolumn{4}{|c|}{ Dependent variable = SUED } \\
\hline & & Coefficient & $\begin{array}{c}\text { Mean } \\
\text { marginal } \\
\text { effect }\end{array}$ & $\boldsymbol{t}$-stat & \\
\hline warn & - & -2.552 & -0.479 & -2.61 & $\cdots$ \\
\hline sales & + & 58.705 & 11.010 & 6.26 & $\cdots$ \\
\hline sales $\times$ warn & - & -57.742 & -10.829 & -5.89 & $\cdots$ \\
\hline $\boldsymbol{n}$ & & \multicolumn{5}{|c|}{956} \\
\hline Intercept / Other Controls & & \multicolumn{5}{|c|}{ Yes / Yes } \\
\hline Pseudo R / ROC Area & & \multicolumn{5}{|c|}{$25.0 \% / 0.821$} \\
\hline
\end{tabular}

